Journal of Educational

and Psychological Sciences

Volume (5), Issue (25): 30 Jul 2021

P: $43-64$

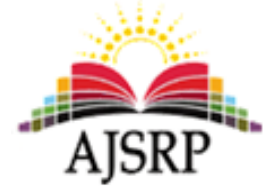

ISSN: 2522-3399

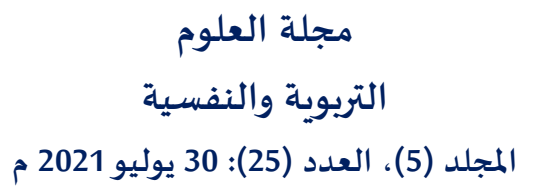

ص: 43 - 64

\title{
The reality of integrating e-learning in the educational environment for teaching Arabic to the primary stage from the point of view of Arabic language teachers in the State of Kuwait
}

\author{
Ahmad Abdullah Al-Enzi \\ Ministry of Education || Kuwait
}

\begin{abstract}
The current study aimed to identify the reality of integrating e-learning in the educational environment for teaching Arabic to the elementary stage from the point of view of Arabic language teachers in the State of Kuwait, and the study followed the descriptive and analytical approach, and consisted of (334) teachers, by the random cluster method. Electronic learning in the educational environment for teaching Arabic to the primary stage from the point of view of Arabic language teachers in the State of Kuwait came to a medium degree, and there was no difference of statistical significance for the responses of the study sample on the reality of integrating e-learning into the educational environment to teach Arabic for the primary stage from the point of view of Arabic language teachers In the State of Kuwait, it is attributed to the variable of gender and years of experience, and the existence of a statistically significant difference for the responses of the study sample on the reality of integrating e-learning into the educational environment for teaching the Arabic language to the primary stage from the point of view of Arabic language teachers in the State of Kuwait attributable to the scientific qualification variable in all fields except the tool as a whole. The difference is in favor of those with postgraduate qualifications, the study recommended holding training courses for teachers related to e-learning, employing it in the educational process, encouraging teachers to design computerized educational programs based on e-learning, developing attitudes of Arabic language teachers towards using e-learning in teaching by holding training courses, and reducing teachers'shares.
\end{abstract}

Keywords: e-learning, educational environment, Arabic language, elementary school, teachers of the Arabic language,

Kuwait.

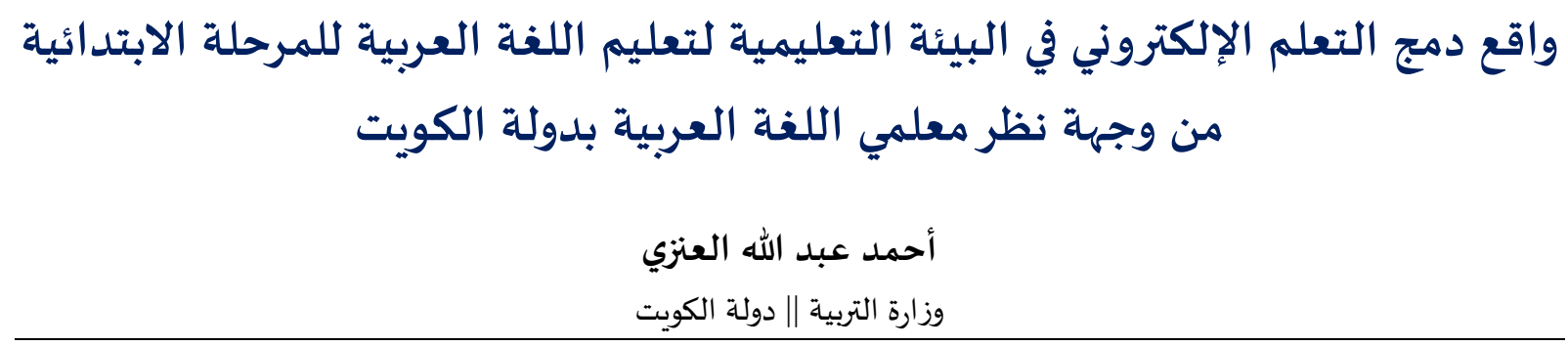

المستخلص: هدفت الدراسة الحالية للتعرف على واقع دمج التعلم الإلكتروني في البيئة التعليمية لتعليم اللغة العربية للمرحلة الابتدائية من وجهة نظر معلمي اللغة العربية بدولة الكويت، واتبعت الدراسة المنهج الوصفي التحليلي، وتمثلت الأداة في استبانة، تم

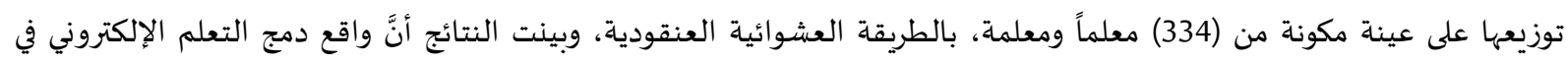

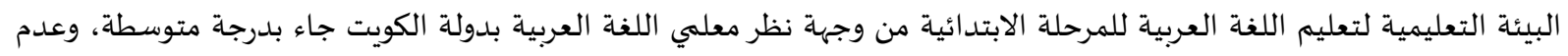
وجود فرق ذو دلالة احصائية لاستجابات عينة الدراسة على واقع دمج التعلم الإلكتروني في البيئة التعليمية لتعليم اللغة العربية 


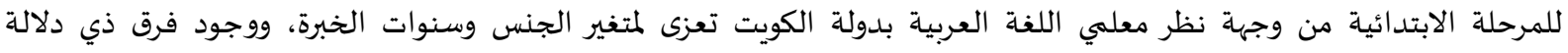

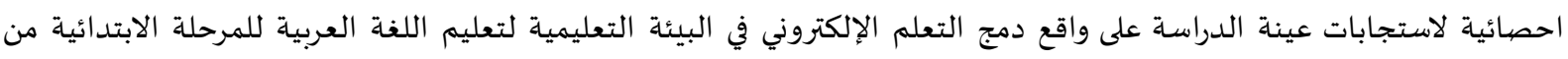

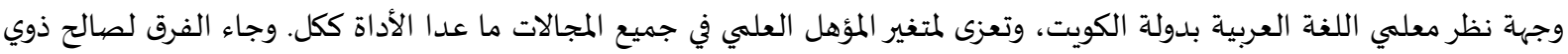

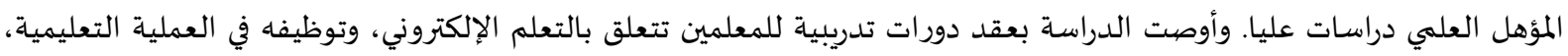

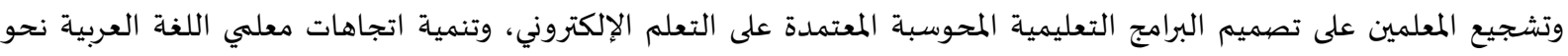
استخدام التعليم الإلكتروني في التدريس من خلال عقد الدورات التدريبية، وتخفيض أنصبة المعلمين ليتمكنوا من تفعيل استخدام التعلم الإلكتروني في التدريس.

الكلمات المفتاحية: التعلم الإلكتروني، البيئة التعليمية، اللغة العربية، المرحلة الابتدائية، معلمو اللغة العربية، دولة الكويت.

مقدمة

في ظل التقدم التقني للمعلومات والاتصالات، والتطور الذي أحدثه في كل المجالات، والتغيرات السريعة التي حدثت على مختلف نواحي الحياة، ارتأت الكثير من الدول إعادة النظر في طرائق التدريس التقليدية المتبعة فيها،

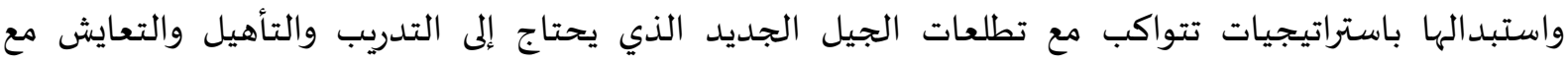
التقنيات الحديثة، وبدأت تخطو خطوات واسعة في مجال تطبيق التعليم الإلكتروني في التعليم.

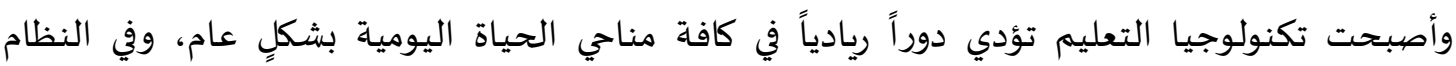
التعليمي بشكل خاص، فقد ظهرت كثير من الأنظمة التعليمية التي تبنت استخدام تلك التكنولوجيا كوسائط ناقلة

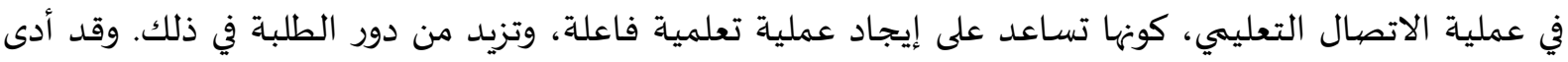
هذا إلى ظهور مفاهيم جديدة في عالم التعليم التي ساعدت الطلبة على التعلم في المكان الذي يريدونها وفي الذيان الزمان

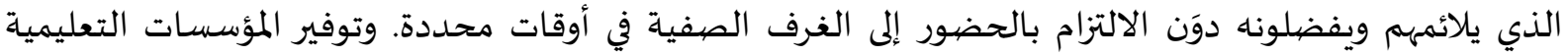

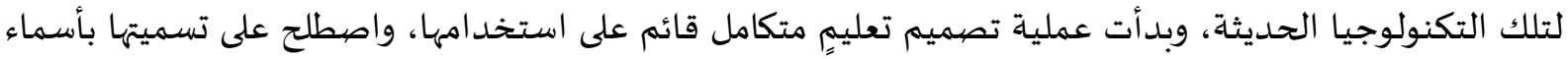

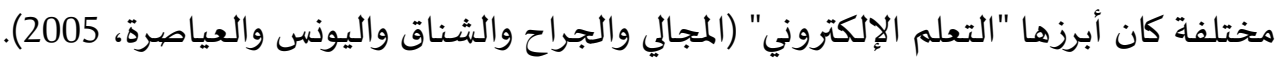

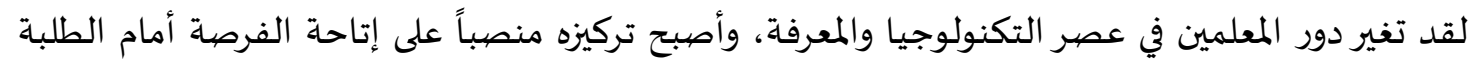

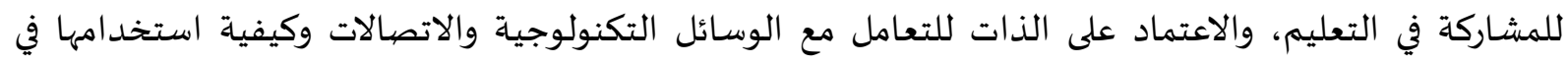

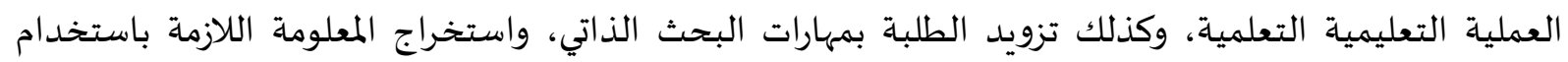

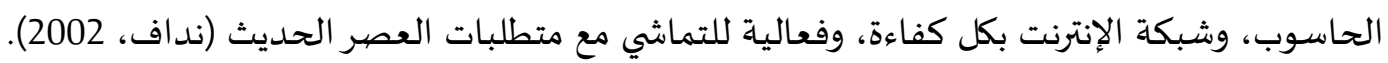

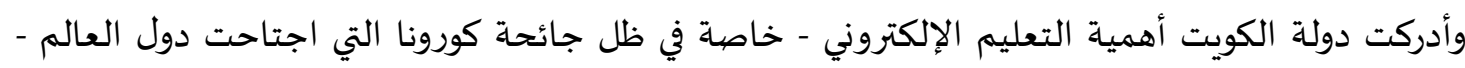

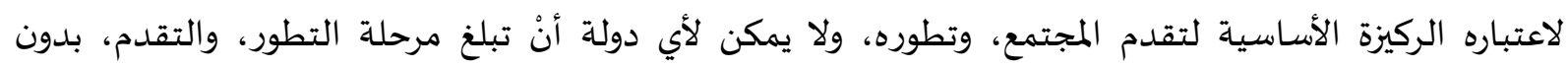

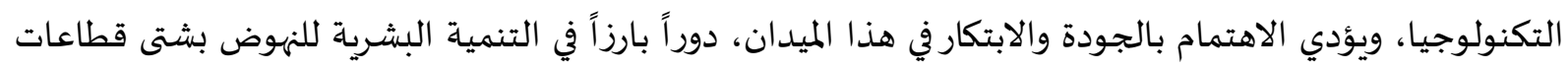
الدولة، فنجاح التعليم يرتبط بعناصر كثيرة، بعضها متصل بهيكلية، ومنظومة التعليم الاكاديمية والعلمياة، وبعضهيا

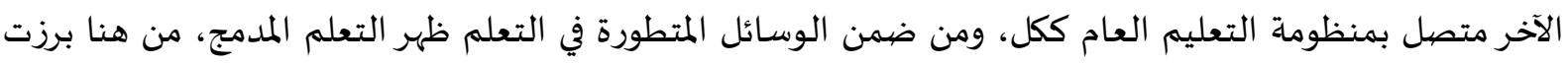

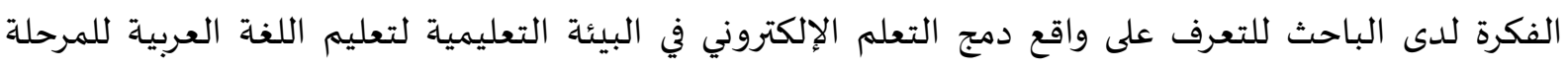
الابتدائية من وجهة نظر معلمي اللغة العربية بدولة الكويت.

مشكلة الدراسة وأسئلتها لاحظ الباحث أثناء عمله بالتدريس وجود بعض معلمي اللغة العربية الذين حاولوا استخدام التعلم

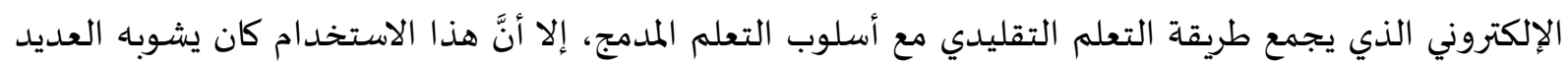


من المعوقات، نظراً للوقت الطويل الذي يتطلبه استخدام التعلم الإلكتروني، والتجهيزات التي قد تختلف من مدرسة

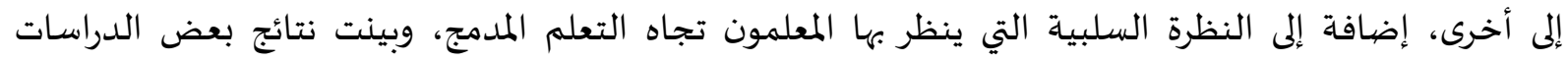

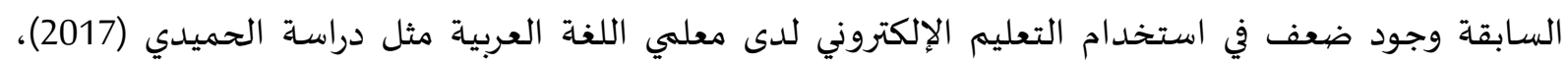

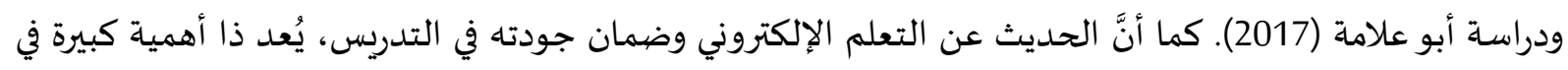

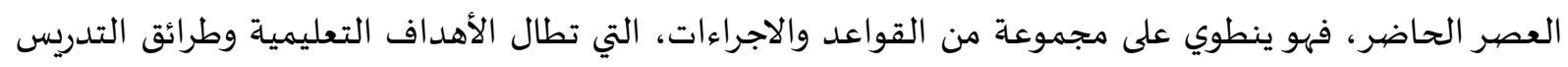

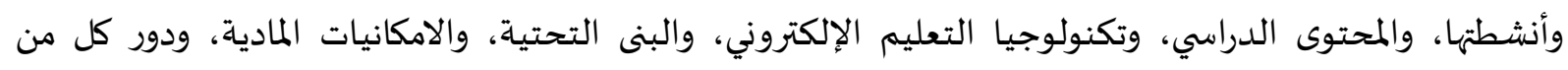

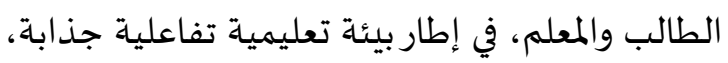
ومن هنا جاءت فكرة الدراسة لدى الباحث للتعرف على واقع دمج التعلم الإلكتروني في البيئة التعليمية

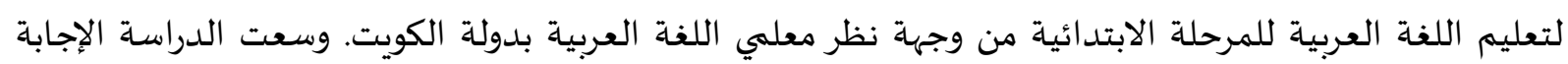
عن السؤالين الآتيين: 1. ما واقع دمج التعلم الإلكتروني في البيئة التعليمية لتعليم اللغة العربية للمرحلة الابتدائية من وجهة نظر

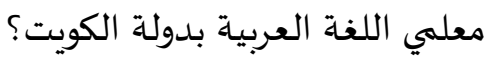
2. هل يوجد فرق ذو دلالة احصائية عند مستوى الدلالة (م =0.05) في واقع دمج التعلم الإلكتروني في البيئة

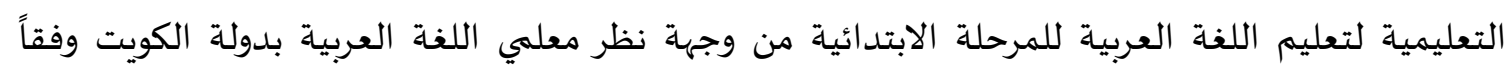

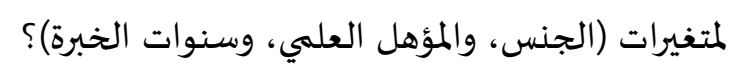
أهداف الدراسة:

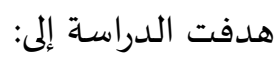

1. التعرف على واقع دمج التعلم الإلكتروني في البيئة التعليمية لتعليم اللغة العربية للمرحلة الابتدائية من

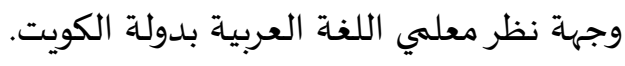
2. الكشف عن الفروق في متوسطات تقديرات أفراد عينة الدراسة لواقع دمج التعلم الإلكتروني في البيئة

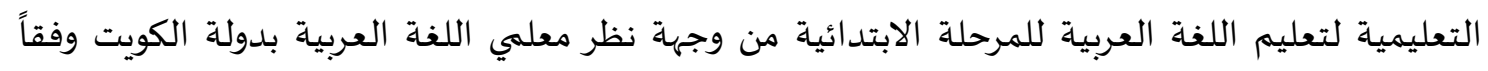

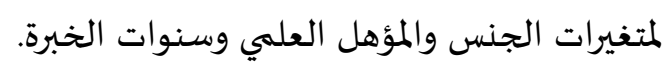

أهمية الدراسة:

تكمن أهمية الدراسة في الأمور الآتية:

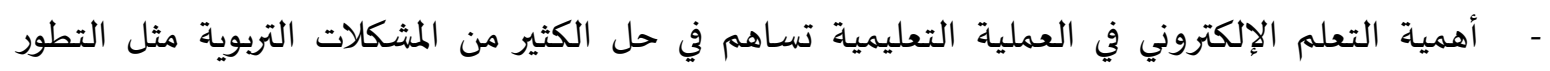

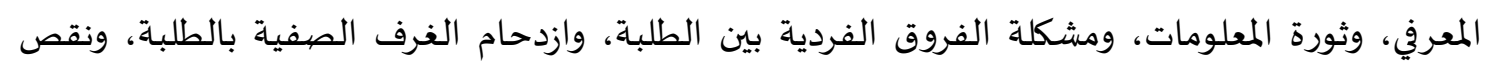
عدد المعلمين المؤهلين، والمدربين.

تقديم التوصيات والمقترحات لمتخذي القرارفي وزارة التربية القائمين على العملية التعليمية في دولة الكويت. تسعى النتائج إلى تقديم تصور عن الوضع الحالي لواقع دمج التعلم الإلكتروني في بيئات التعلم.

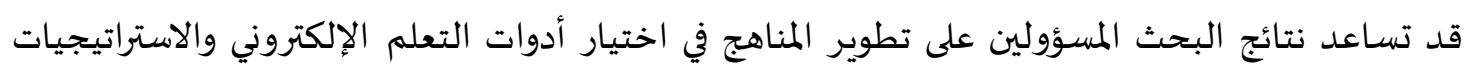
المناسبة لدمجها في المناهج. من الممكن أن ترشد النتائج متخذي القرار إلى إعادة تطوير بيئات التعلم التقليدية في ضوء التطور المستمر في أدوات التعلم الإلكترونية. 


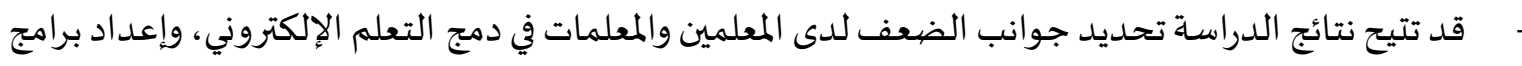
تدربية تطويرية تسعى لإعدادهم في استخدام أدوات التعلم الإلكتروني لمواكبة مهارات القرن الحادي لمعادي

$$
\text { والعشرين. }
$$

حدود الدراسـة:

$$
\text { تقتصر حدود الدراسة على الآتي: }
$$

الحدود الموضهوعية: واقع دمج التعلم الإلكتروني في البيئة التعليمية لتعليم اللغة العربية للمرحلة الابتدائية

من وجهاة نظر معلمي اللغة العربية بدولة الكويت.

الحدود البشرية: معلمي اللغة العربية في المرحلة الابتدائية بمنطقة الأحمدي التعليمية بدوبة بلدولة الكويت.

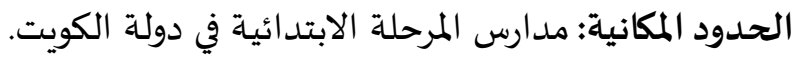

الحدود الزمانية: تم تطبيق هذه الدراسة خلال الفصل الدراسي الأول من العام الدراسي 2021/2020م.

مصطلحات الدراسـة:

فيما يأتي تعريف المصطلحات الواردة في الدئة الدراسـة:

- التعليم الإلكتروني:"التعلم الذي يقوم على التفاعل مع المادة الدراسية والمعلم من خلال وسائط إلكترونية

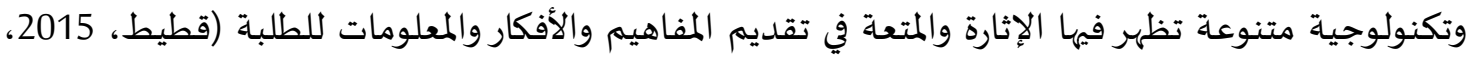

(176

O التعليم الإلكتروني- إجرائيا- التعليم الذي يعتمد على استخدام الوسائط الإلكترونية في الاتصال بين

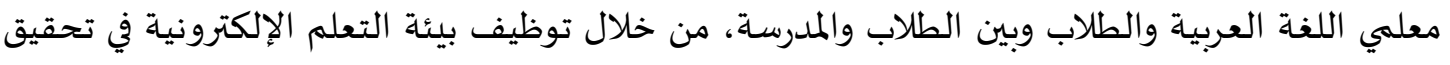

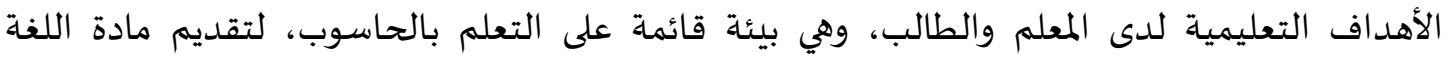

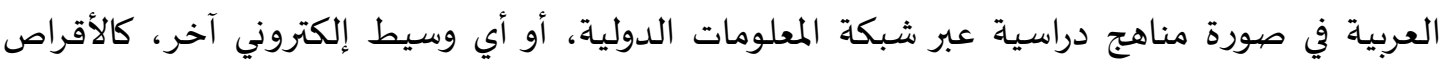

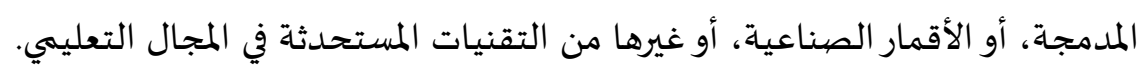

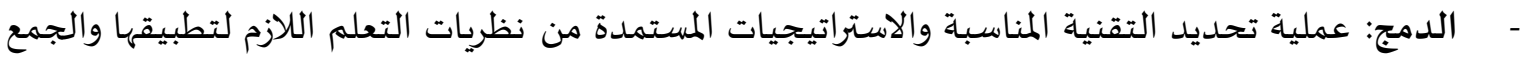

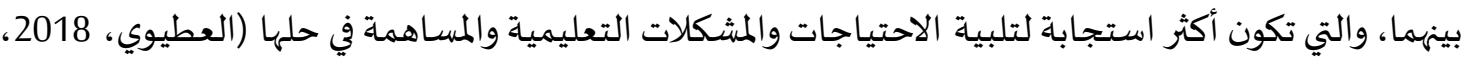

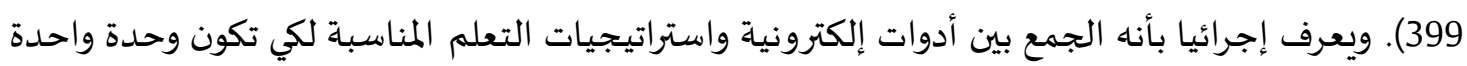

$$
\text { لتعزيز التعلم في البيئة التعليمية. }
$$

- البيئة التعليمية: عبارة عن المكان والمساحة التي تمثلها المدرسة التي تضم الصفوف الدراسية والمكتبة،

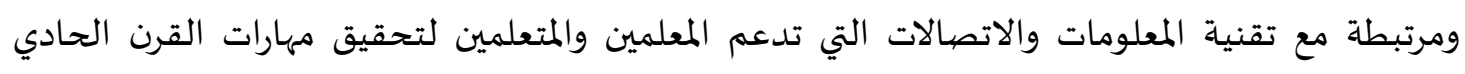

$$
\text { والعشرين (حلس، 2018، 10). }
$$

- المرحلة الابتدائية: المرحلة الأولى من مراحل التعليم بدولة الكويت وتشمل الصفوف الأول والثاني والثالث

والرابع والخامس. 
يُعد التعليم الإلكتروني طريقة للتعليم باستخدام آليات الاتصال الحديثة من حاسب وشبكاته ووسائطه

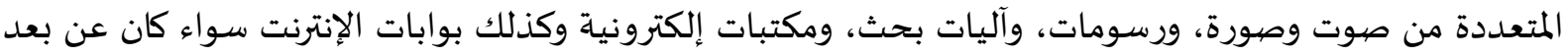

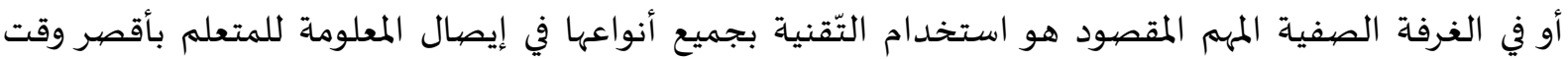
وأقل جهد وأكبر فائدة (Attesseri, 2009). يهدف التعليم الإلكتروني إلى تقديم محتوى تعليمي رقمي متعدد الوسائط (نصوص مكتوبة، أو منطوقة،

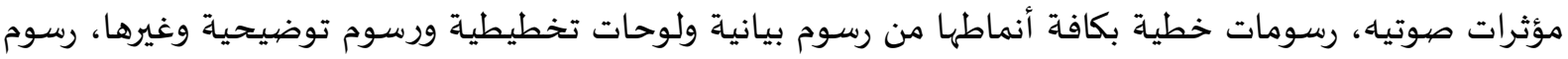

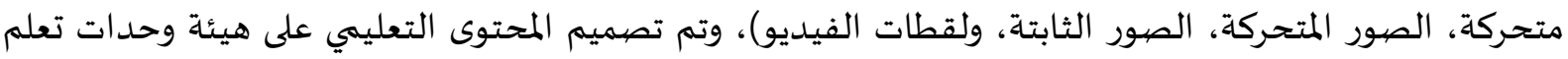

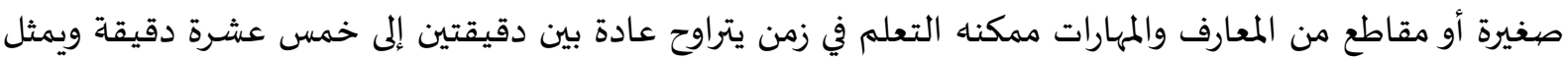

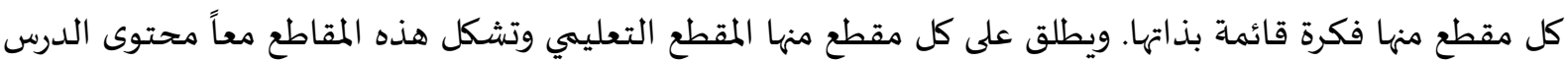

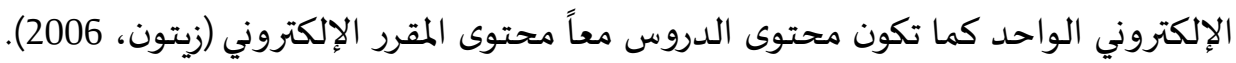

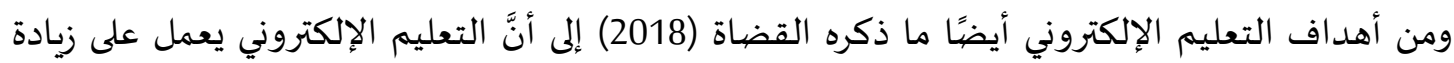

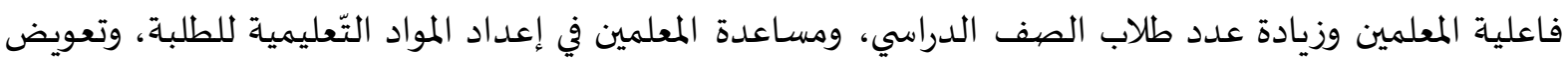

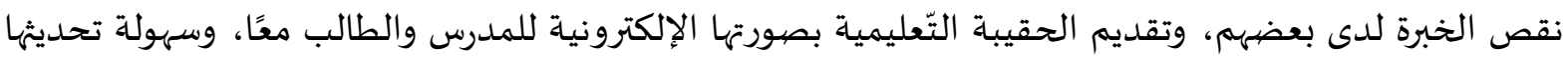

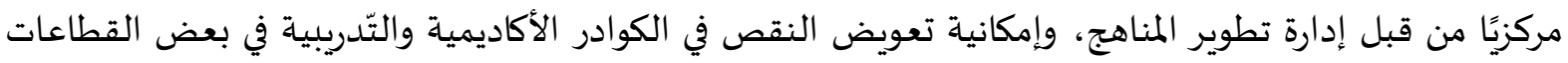

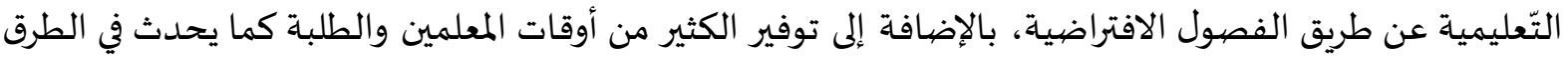

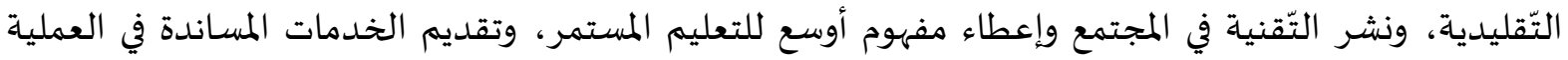

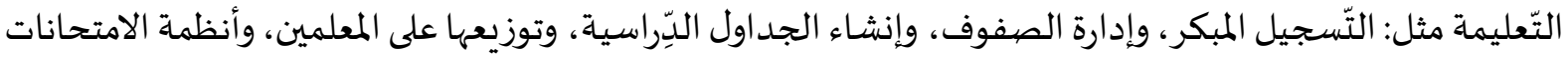

والتّقويم وتوجياه الطلبة وغيرها.

وتأخذ عملية الدمج بين التعلم الإلكتروني، والتعلم الصفي عدة أشكال منها أنْ يبدأ المعلم بالتمهيد للدرس

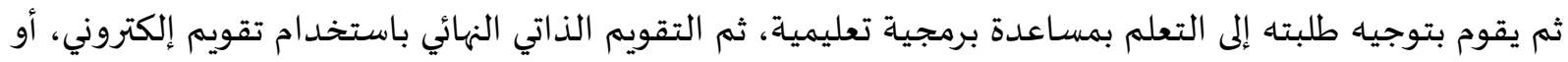

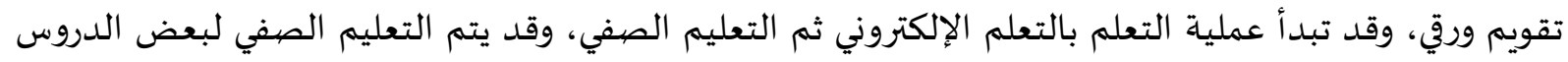
(Carman, التي تتناسب معه والتعلم الإلكتروني لموضوعات أخرى تتوافر لها أدوات التعلم الإلكتروني ثم يتم التقويم

يتمثل استخدام التقنية في التعليم غالباً في الحاسوب، ولاستخدامه في التعليم عدة مبررات، منها (العريفي

وقطيط والخلايلة، 2016):

- أداة مناسبة لجميع فئات الطلاب: سواء الموهوبين منهم أو العاديين أو بطيئين التعلم أو المعوقين كل حسب

مستواه وقدراته، ومهاراته دوافعاه، وسرعة تعلماه، وانضباطه وقدرته على حل المشكلات.

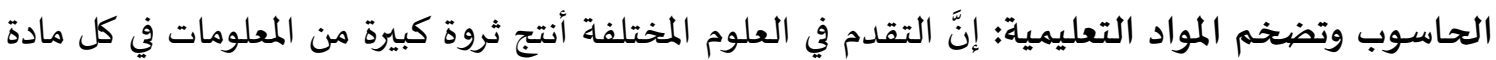
تعجز المجلدات عن احتوائها. ويعتبر الحاسوب أنسب وسيلة تستخدم لمواجهة هذه الظاهرة لما له من قدرة

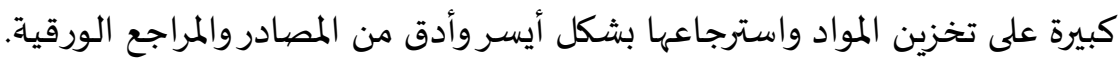

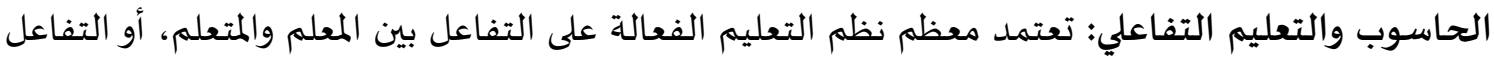
بين المتعلم والتقنية، ويتطلب التفاعل استقبال المعلومات المعروضة وتسجيل استجابة المتعلم ومن ثم 
إعطاءه التغذية الراجعة؛ ليتأكد من صحة استجابته فيتعزز تعلمه، وعندما يخطئ تنهه البرمجية إلى أنَّ

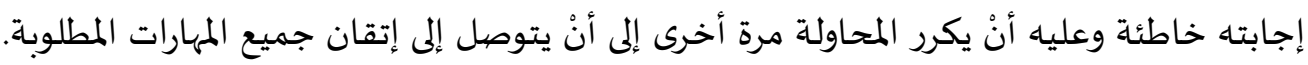

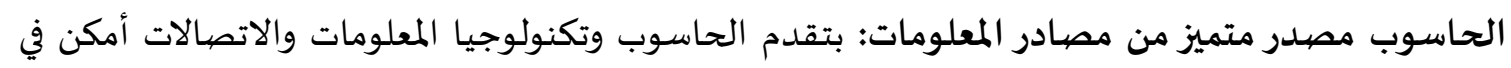

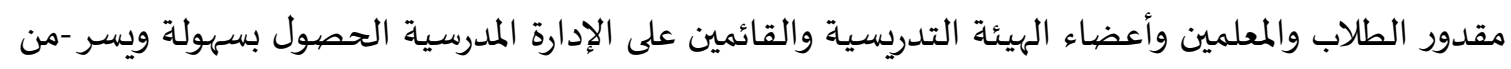

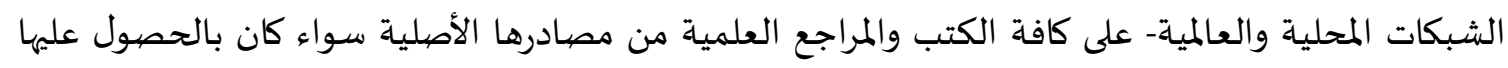

$$
\text { مباشرة أو بالاستعارة أو بالشراء. }
$$

إنَّ التعلم الإلكتروني يستطيع أنْ يقدم مميزات قيَّمة للمتعلمين تدعم تطورهم التمار أثناء العملية التعليمية في

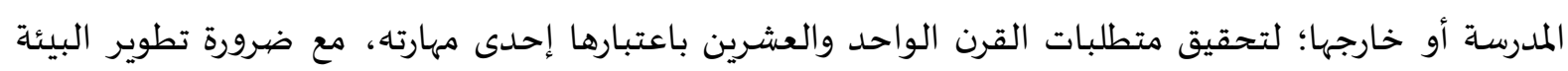

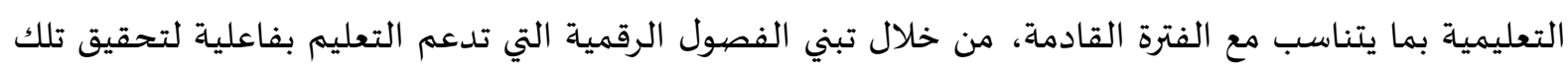

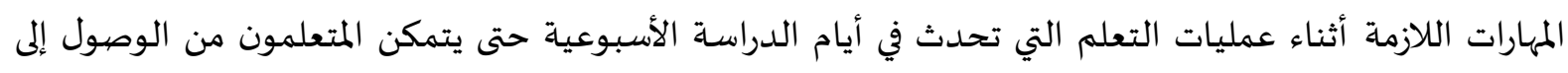

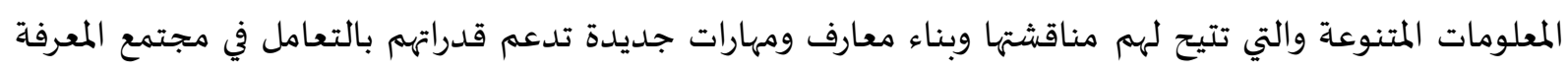

(العطيوي، 2018).

هناك عدد من المبرات التي تدفع إلى ضرورة تدريب المعلمين على استخدام التعلم الإلكتروني وتنمية

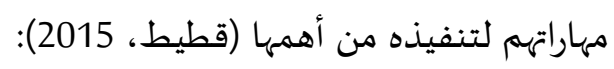
- الحاجة للتنمية المهنية: يُعد التعلم الإلكتروني وسيلة لتنمية مهية مهارات المعلم وقدراته المهنية؛ إذ يُقدم للمعلم من خلال الإنترنت مصادر عديدة وبرامج وبحوث ودراسات تساعده على تنمية مهاراته وقدراته المختلفة.

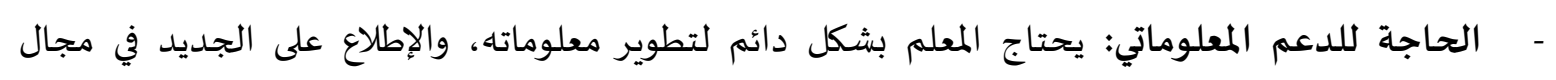

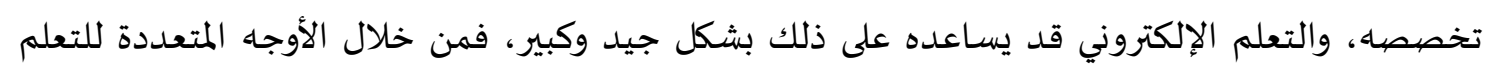

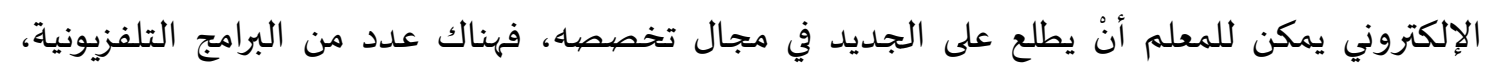
والحاسوبية المعدة لذلك.

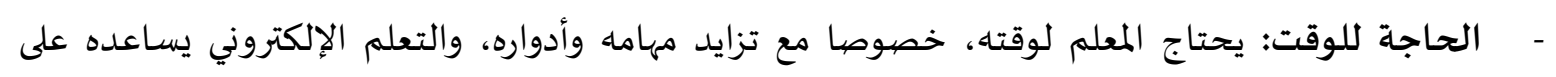
جمع معلوماته، بل ويقدم له عدداً من مخططات الدروس الجاهزة التي تساعده على الماتى توفير وقته لمتابعة أعمال طلابه داخل وخارج المدرسـة. - الحاجة لتأكيد نجاح التدريس: يحتاج المعلم لمصادر عديدة لتأكيد نجاح عمليات التدريس التي يقوم بها، ويقدم له التعلم الإلكتروني عددا من المصادر التي تتيح له ذلك من مصادر لطلابه، وقوائم لتقويم أدائه

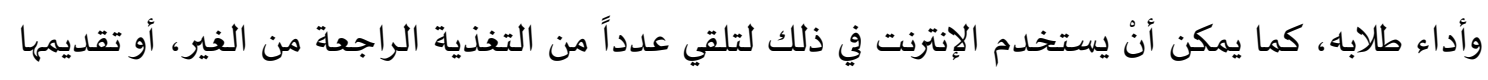

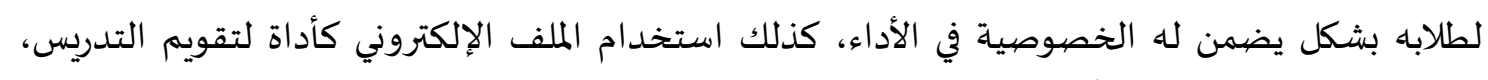
حتى أنه أصبح عنصراً رئيسياً ضمن الخطوات التي تستخدمها لهيه الهيئة الدولية لمعايير مهنة التدريس.

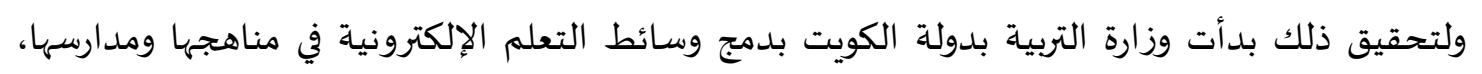

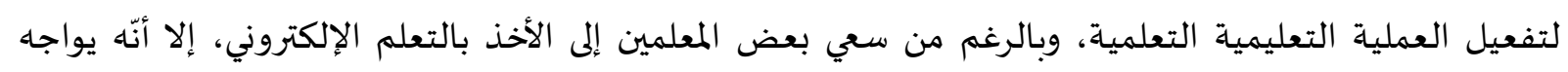

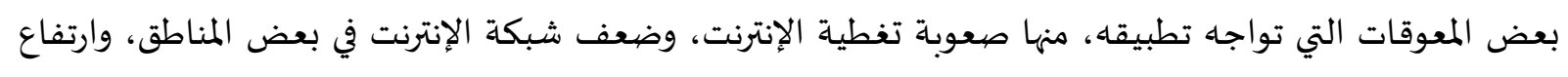

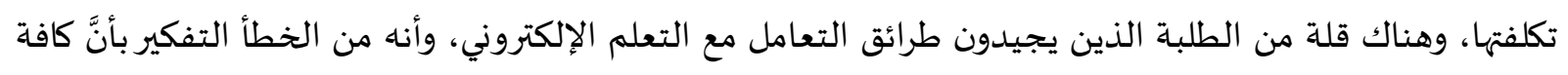

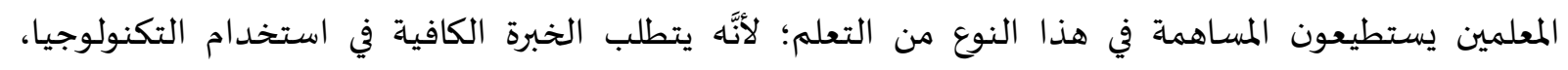

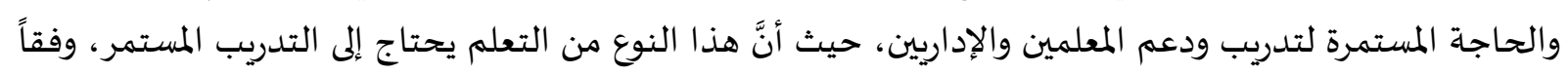
للتطور التكنولوجي (القضياة، 2008). 
ثانياً- الدراسـات السابقة:

تناول هذا الجزء من الفصل، الدراسات السابقة ذات العلاقة بالتعلم الإلكتروني، وتم ترتيبها زمنياً من

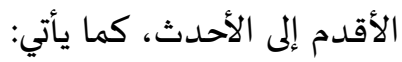

دراسة يوين وما (Yuen \& ma, 2008) هدفت تعرف مدى تقبل المعلمين لتكنولوجيا التعليم الإلكتروني،

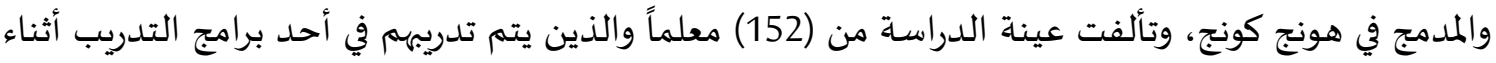
الخدمة للمعلمين في هونج كونج. وتم تصميم استبيان للتعرف على تقبل المعلمين واتجاهاتهم نحو التعليم الإلكتروني. كما تم إعداد نموذج لفهم طبيعة عملية تقبل المعلمين للتعليم الإلكتروني ويتكون هذا النموذج هونيم من خمس مفاهيم: النية لاستخدام التكنولوجيا، الفائدة المدركة، والسهولة المدركة في الاستخدام، المعايير

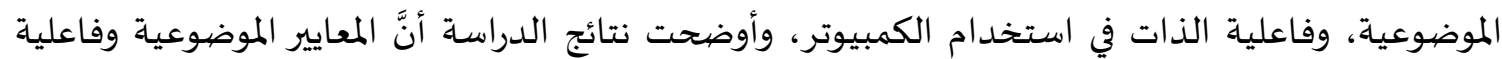
الذات في استخدام الحاسب الالي تعتبر من أهم المكونات أو المكونات الرئيسة في النموذج. وأشارت نتائيج

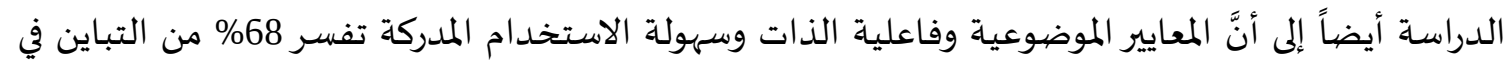

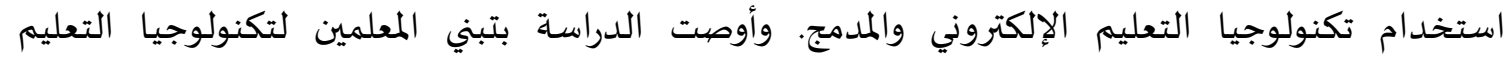
الإلكتروني والمدمج، وعقد دورات تدريبية للمعلمين في مجال التعليم الإلكتروني.

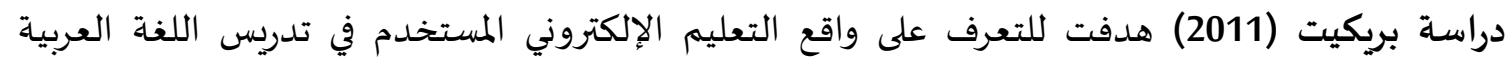
بالمرحلة الثانوية من وجهة نظر معلمي ومشرفي اللغة العربية ومعوقات استخدامه، تم استخدام المنهج

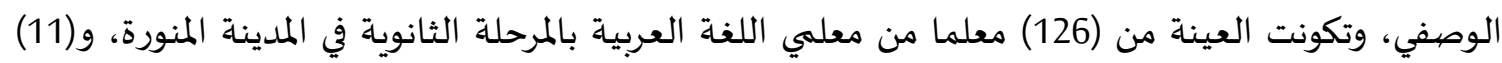

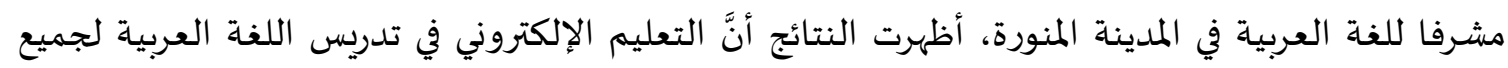

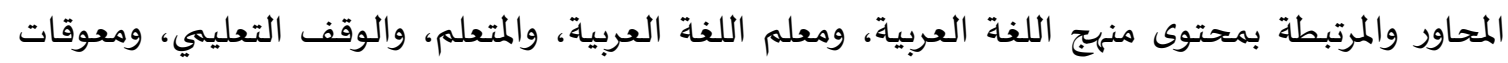

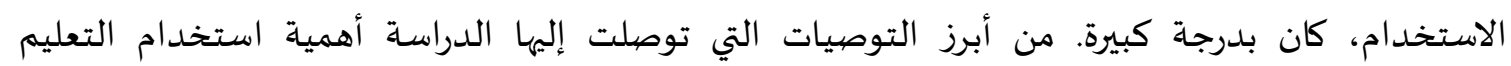

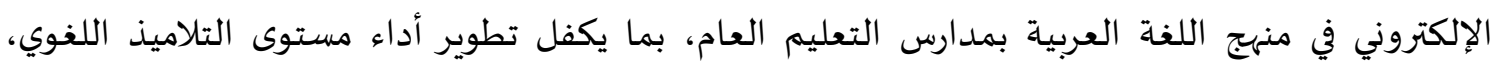

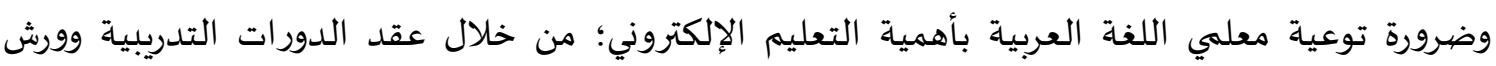
العمل، للتعامل مع الإنترنت والوسائل التعليمية الحديثة.

دراسة جبر والعرنوسي (2014) هدفت للتعرف على معوقات تطبيق التعلم المدمج، وإعداد تصميم مقترح

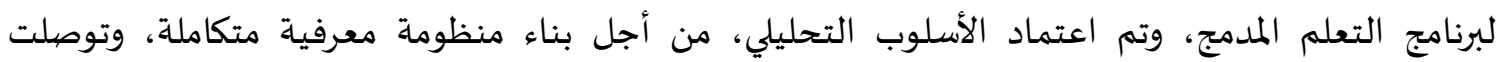

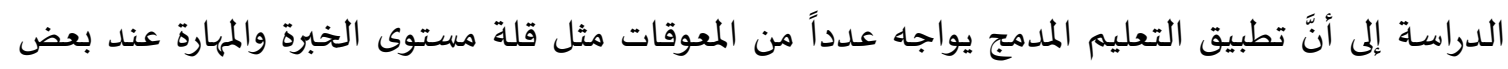

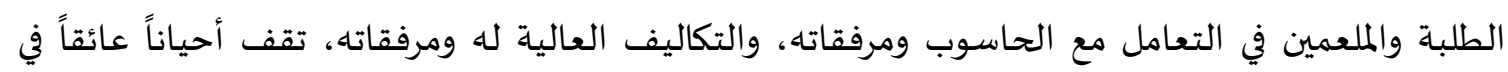

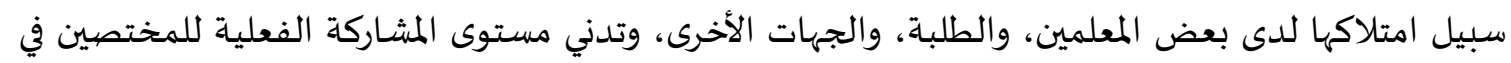

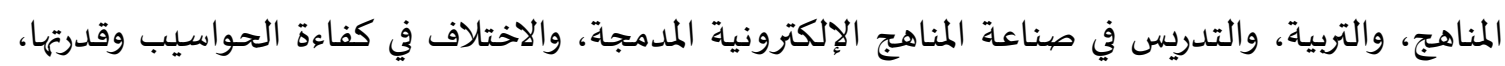

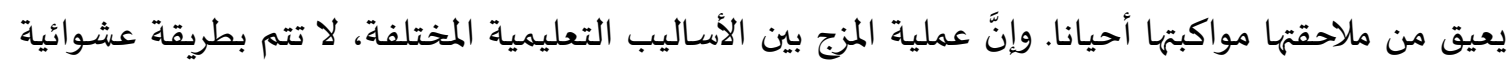
او مزاجية، بل بإسلوب علمي منظم ومتجانس، تحكمها عدة معايير وضوابط، تتعلق بمتطلبات الموقف

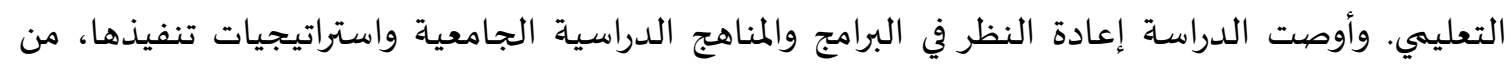

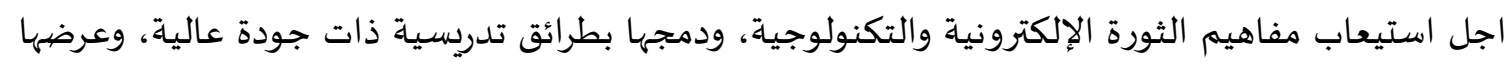

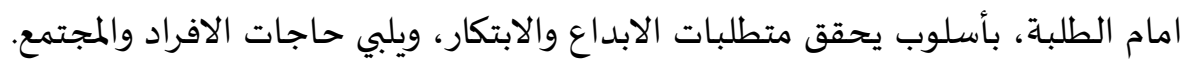
دراسة الدليمي (2015) هدفت إلى التعرّف على درجة ممارسة معلمي اللغة العربية لمهارات التعلم الإلكتروني

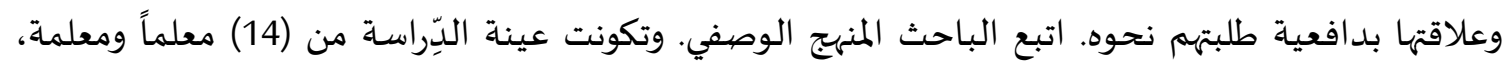


و(292) طالباً وطالبة. لتحقيق أهداف الدِّراسة طور الباحث أداتين، إحداهما للمعلمين وتكونت من (62)

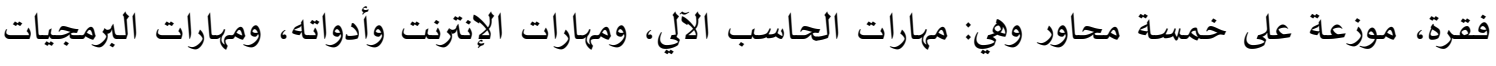

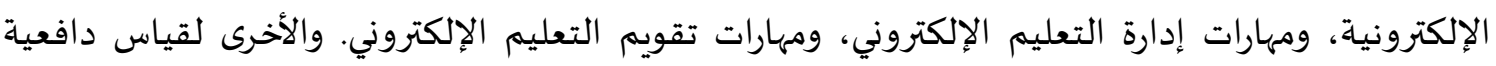

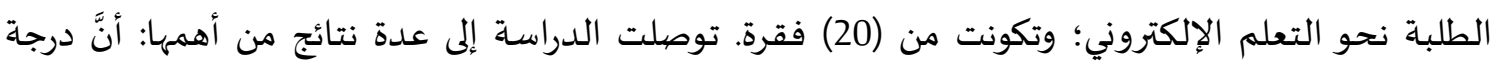

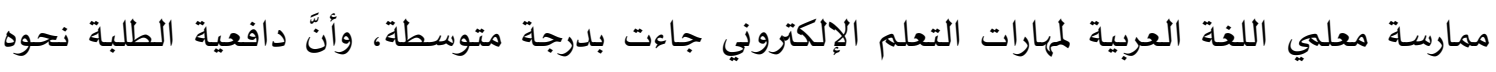

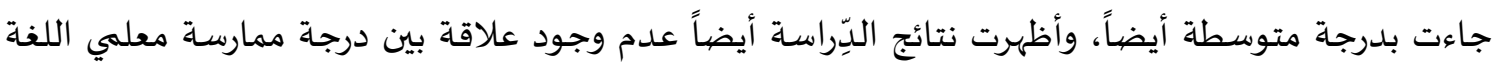

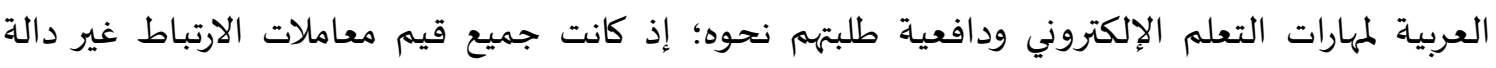

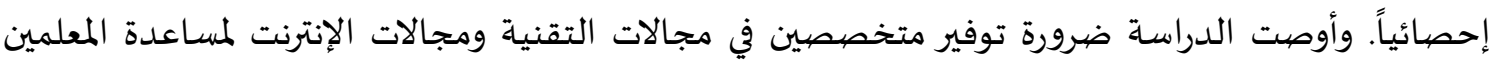

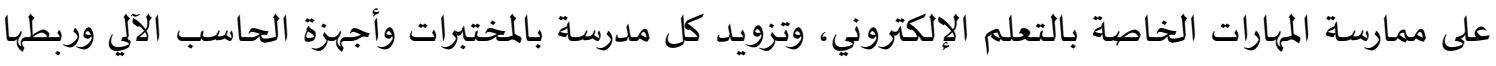

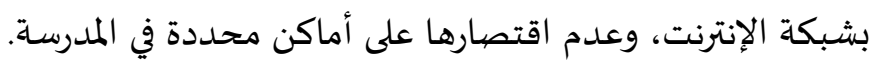

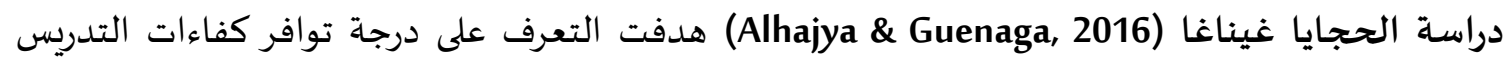

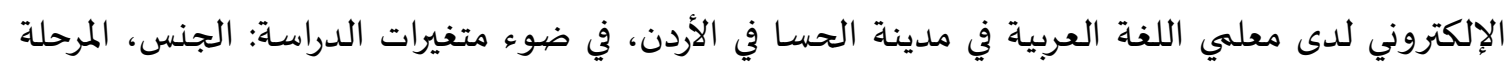

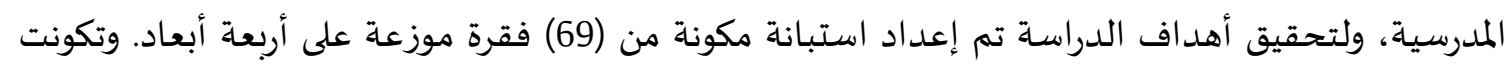

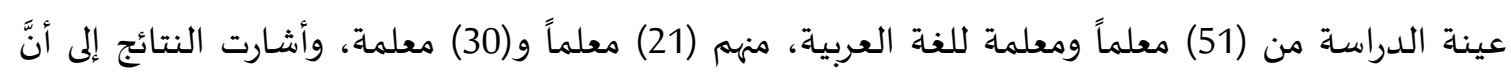

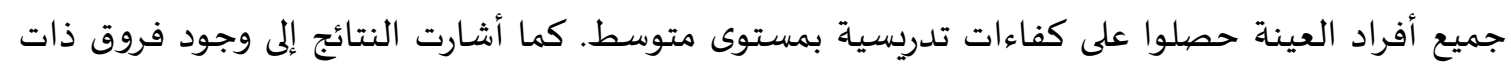

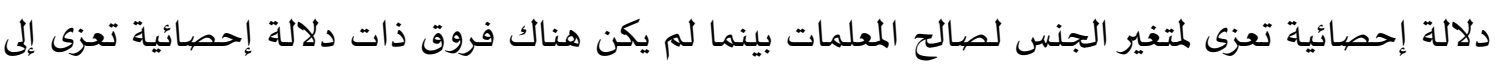
المرحلة المدرسية. وكانت هناك فروق ذات دلالة إحصائية تعزى للتجربة لصالح المعلمين الذكور الذين لديهيم خبرة 5-1 سنوات. وأوصت الدراسة بتنظيم دورات تدريبية متخصصية في التدريس الإلكتروني للمعلمين لاكتساب كفاءات التدريس الإلكتروني، وإدراج كفاءات التدريس الإلكتروني في مقررات الجامعات المخصصية لإعداد المعلمين. دراسـة أبو علامة (2017) هدفت للتعرف على واقع استخدام التعليم الإلكتروني في تدريس مادة اللغة العربية لطلاب الشهادة الثانوية السودانية، ومدى مساهمته في تحسين الناتج التعليمي للطلاب، وتم استخدام المنهنج

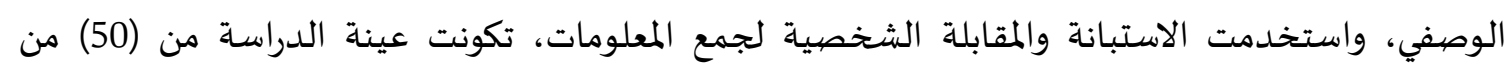

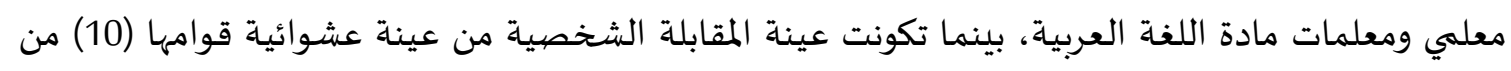

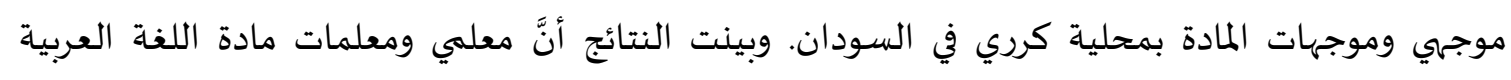

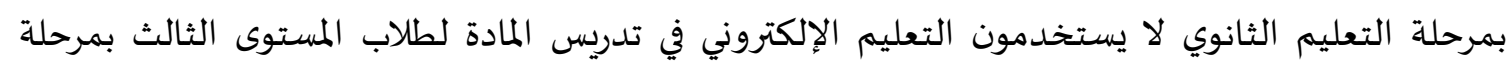

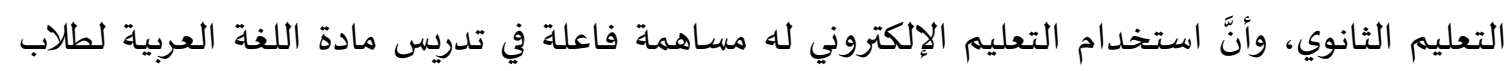

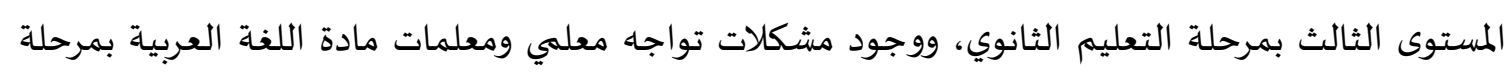

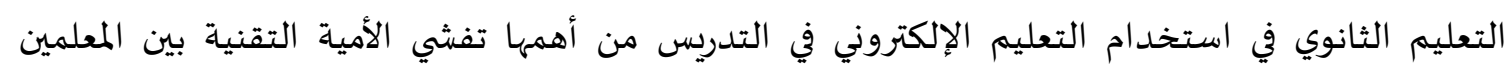

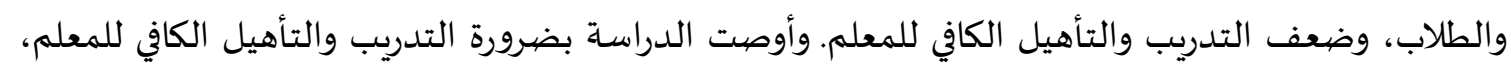
وزيادة التمويل المادي لشراء المعدات اللازمة والأجهزة وتوفيرها. دراسة الحميدي (2017) هدفت التعرّف على درجة امتلاك معلمي اللغة العربية بالمرحلة الثانوية بدولة الكويت للكفايات الإلكترونية من وجهة نظرهم. طبقت الدراسة على عينة عشوائية تضمنت (200) معلم

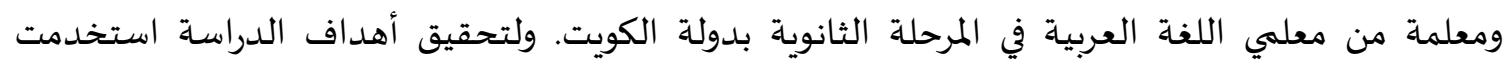

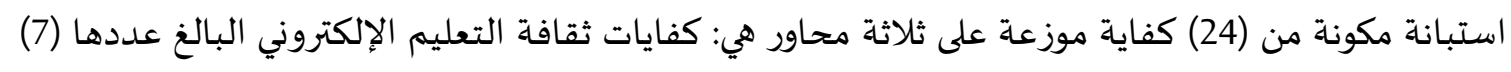


كفايات، والكفايات المتعلقة بقيادة الشبكات والإنترنت البالغ عددها (11) كفاية، وكفايات تصميم البرمجيات

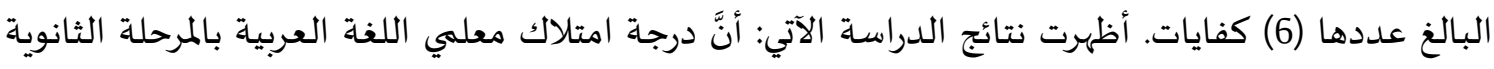

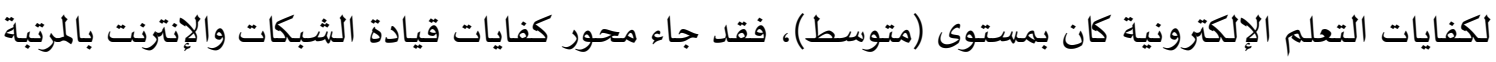

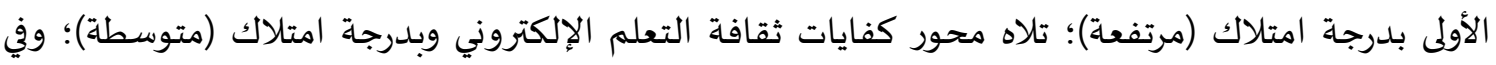

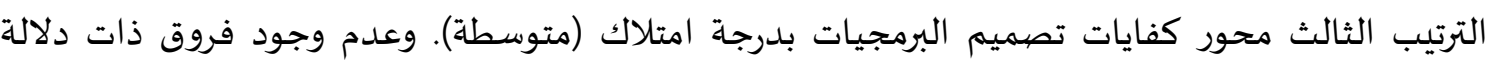
إحصائية في جميع محاور الدراسة تعزى إلى متغير الجنس. وعدم وجود فروق ذاتئ ذات دلاتلة إحصيائية تعزى إلى إلى

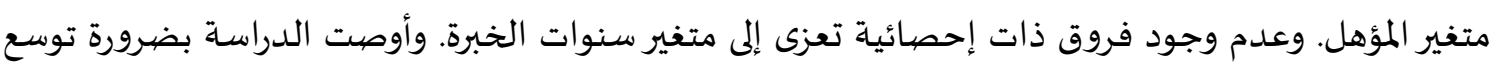

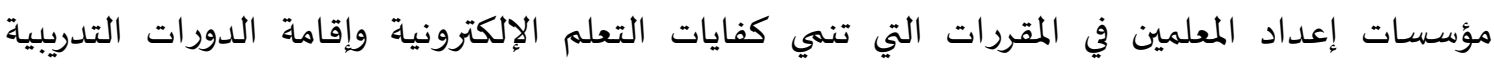
للمعلمين. مؤسيات. دراسة العطيوي (2018) هدفت تعرف واقع دمج التعلم الإلكتروني في البيئة التعليمية من وجهة نظر خريجي

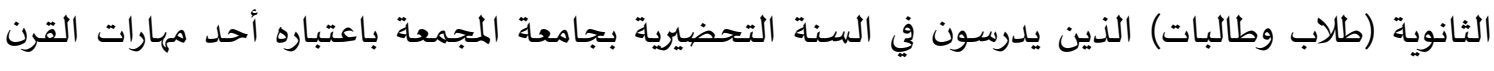
الحادي والعشرين، شمل مجتمع الدراسة جميع الطلاب والطالبات (541)، واستخدم المنهج الكمي التحليلي

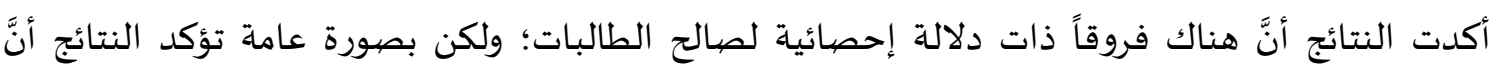

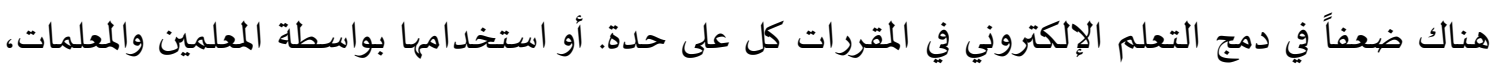

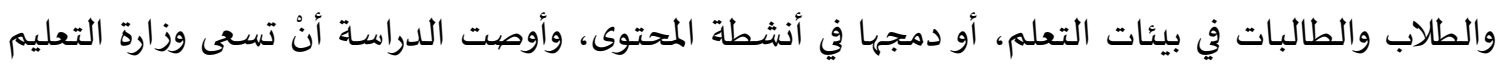
وإدارة المدارس لتبني استراتيجية واضحة تحث المعلمين والمعلمات والطلاب والطالبات على اكتساب فئل مهارات

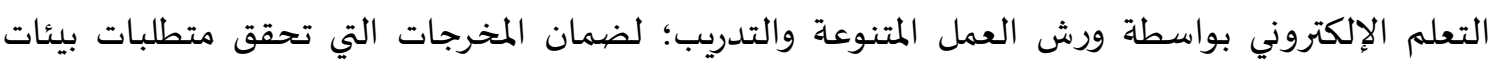

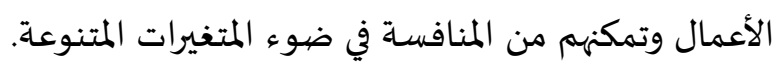

تعقيب على الدراسـات السـابقة: تميزت الدراسة الحالية في تناول موضوع التعلم الإلكتروني من وجهات نظر معلمي اللغة العربية في المرحلة الابتدائية في مدارس دولة الكويت. لم يقف الباحث على دراسة تناولت واقع دمج التعلم الإلكتروني في البيئة التعليمية لتعليم اللغة العربية

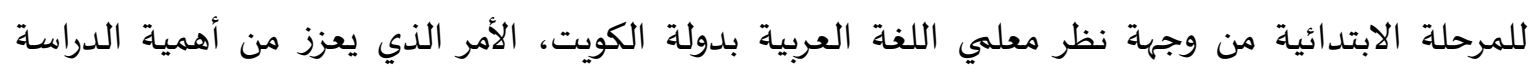
الحالية.

في ضوء عرض الدراسات السابقة استفاد الباحث من تلك الجهود في عدة مجالات منها: الاستفادة من

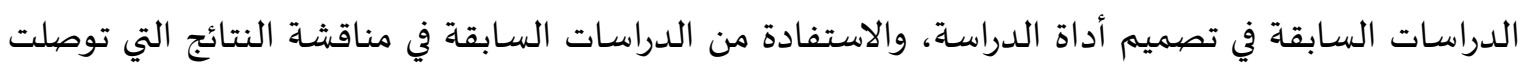

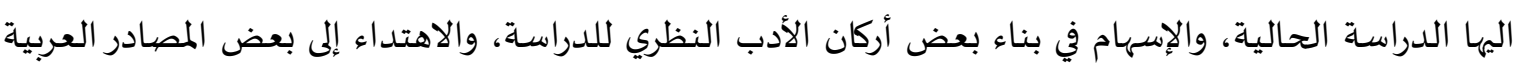

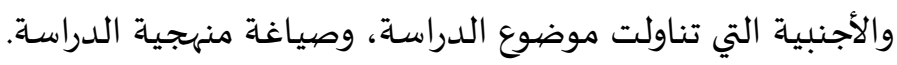

3- منهجية الدراسـة وإجراءاتها.

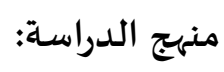

اتبعت الدراسة المنهج الوصفي التحليلي، من خلال تطوير استبانة من أجل تحقيق أغراض هذه الدراسة، ومن ثم تحليلها، والإجابة عن تساؤلات الدراسة، ومناقشة نتائجها وتقديم التوصيات الميات المناسبة. 
مجتمع الدراسة:

تكون مجتمع الدراسة من جميع معلمي اللغة العربية العاملين في المرحلة الابتدائية بمنطقة الأحمدي

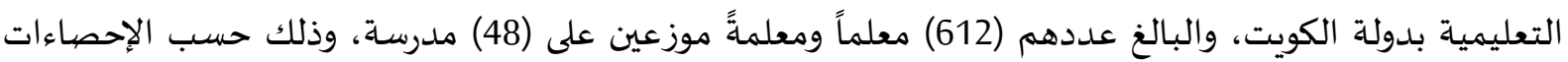

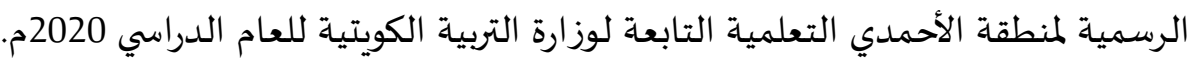

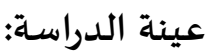

قام الباحث باختيار عينة تكونت من (334) معلماً ومعلمة، بالطريقة العشوائية العنقودية بحيث تم

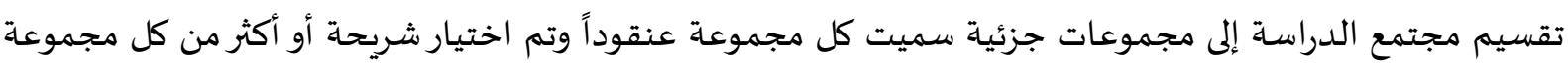

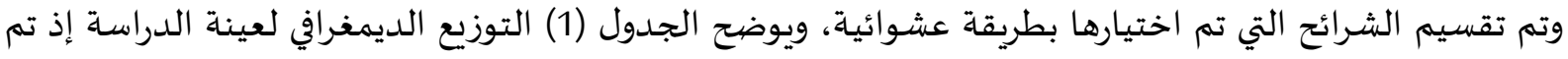

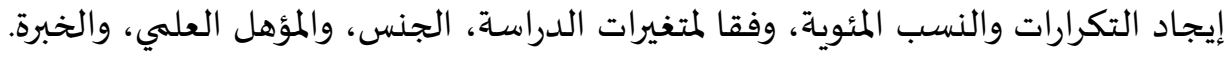

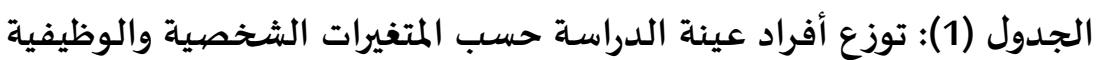

\begin{tabular}{|c|c|c|c|}
\hline النسبة المئوية & التكرار & فئات المتنغير & المتفير \\
\hline$\% 35.9$ & 120 & ذكر & \multirow{2}{*}{ الجنس } \\
\hline$\% 64.1$ & 214 & أنثى & \\
\hline$\% 73.3$ & 245 & بكالوريوس & \multirow{2}{*}{ المؤهل العلمي } \\
\hline$\% 26.7$ & 89 & دراسات عليا & \\
\hline$\% 65$ & 217 & أقل من 10 سنوات & \multirow{2}{*}{ الخبرة } \\
\hline$\% 35$ & 117 & 10 سنوات فأكثر & \\
\hline$\% 100.0$ & 334 & \multicolumn{2}{|c|}{ المجمموع العام } \\
\hline
\end{tabular}

يشير الجدول (1) إلى أنَّ نسبة المعلمات أعلى من نسبة المعلمين، وهذا يشير إلى توافق هذه النسبة مع نسبة

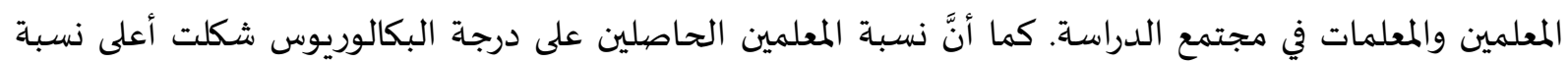

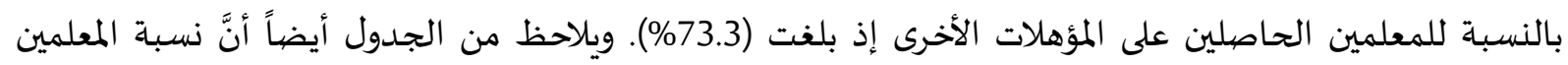
أصحاب الخبرة (أقل من 10 سنوات) شكلت أعلى نسبة بالنسبة للمعلمين من أصحاب الخبرات الأخرى إذ بلغت

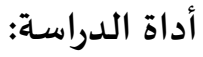

تحقيقا لهدف الدراسة والمتمثل بواقع دمج التعلم الإلكتروني في البيئة التعليمية لتعليم اللغة العربية

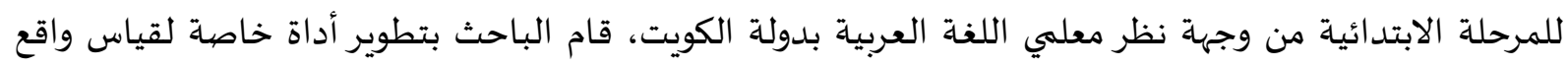

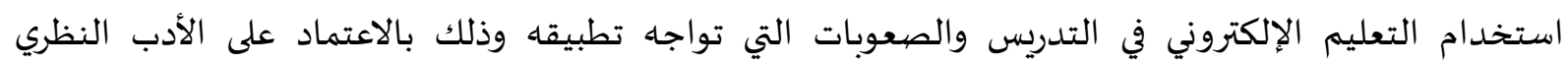

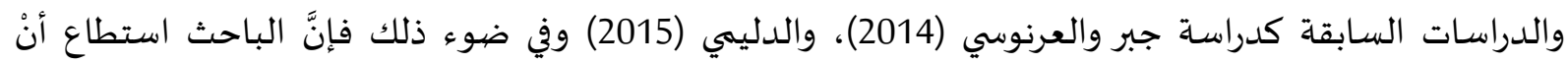

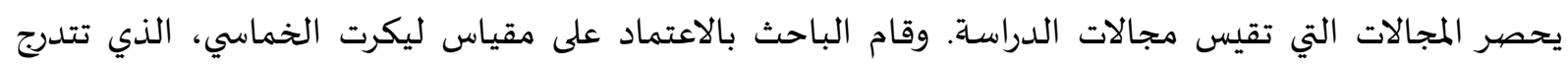

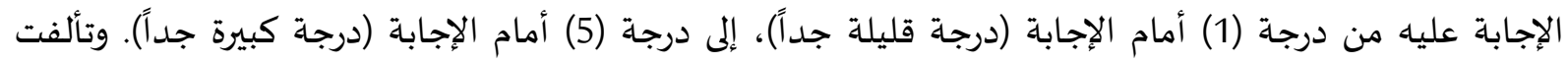

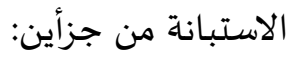
- - الجزء الأول: يتعلق بالمعلومات الشخصية والوظيفية وتتمثل، بالجنس، والمؤهل العلمي، والخبرة. 
- الجزء الثاني: يتعلق بواقع دمج التعلم الإلكتروني في البيئة التعليمية لتعليم اللغة العربية للمرحلة الابتدائية من وجهاة نظر معلمي اللغة العربية بدولة الكويت.

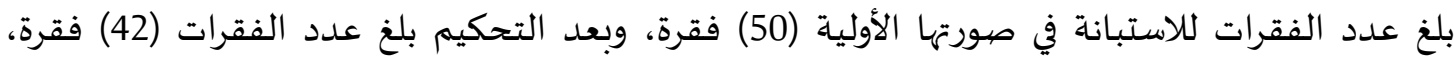
وزعت على أربعة مجالات، لتشمل واقع استخدام التعلم الإلكتروني والصعوبات التي تواجه تطبيقه، وذلك على النحو التالي:

- - الفقرات من (1 - 11) وتقيس مجال (واقع استخدام التعليم الإلكتروني في التدريس).

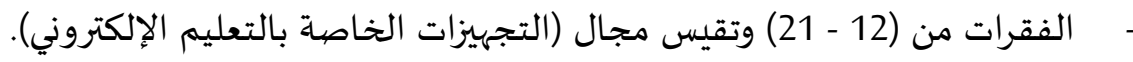

الفقرات من (22 - 28) وتقيس مجال (اتجاهات معلمي اللغة العربية نحو استخدام التعليم الإلكتروني).

- الفقرات من (29 - 42) وتقيس مجال (الصعوبات التي تواجاه استخدام التعليم الإلكتروني في التدريس).

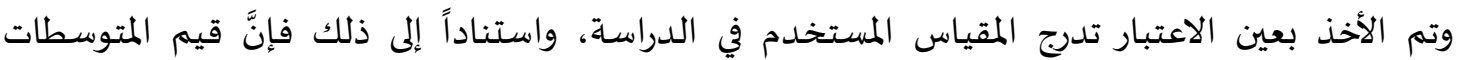
الحسابية التي وصلت اليها الدراسة، تعتمد على معيار مقسم إلى ثلاث فئات متساوية كما يأتي:

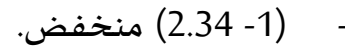
(3.68-2.34) (5-3.68) مرتفع.

صبدق أداة الدراسـة تم عرض أداة الدراسة على عدد من المتخصصين في المجال التربوي في الجامعات الأردنية والكويتية، إذ بلغ عددهم (5) محكمين، لمعرفة مدى صلاحية العبارات المستخدمة لقياس واقع دمج التعلم الإلكتروني في البيئة

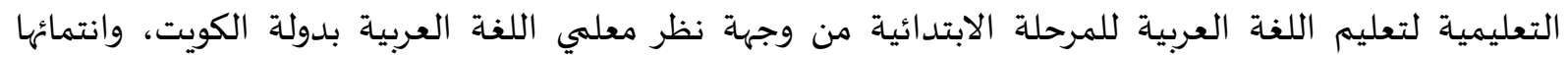

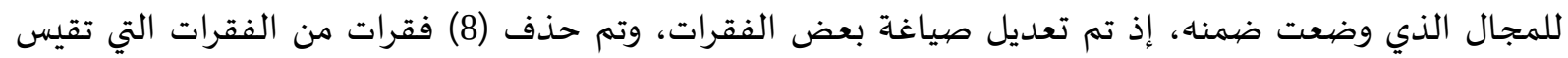

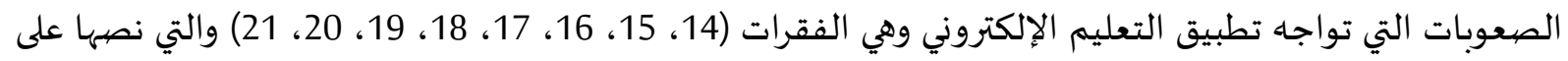
التوالي: (عدم كفاية وقت الحصة الدراسية لعرض جميع محتويات الدرس إلكترونيا، وعدم وجود أدلة إرشادية

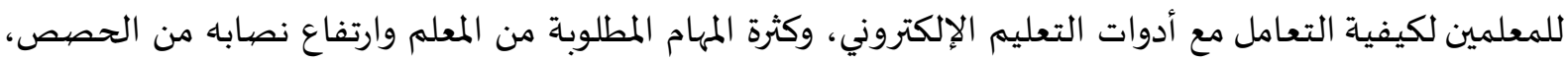

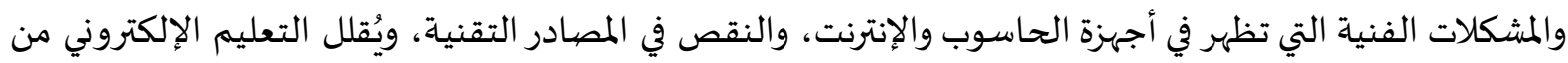

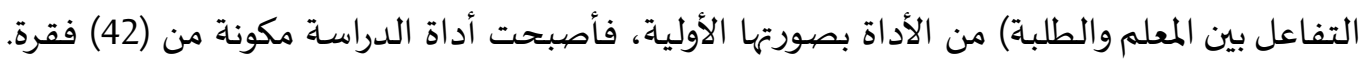

ثبات أداة الدراسـة: تم توزيع أداة الدراسة على عينة استطلاعية من مجتمع الدراسة ومن خارج عينة الدراسة والمتمثلة ب

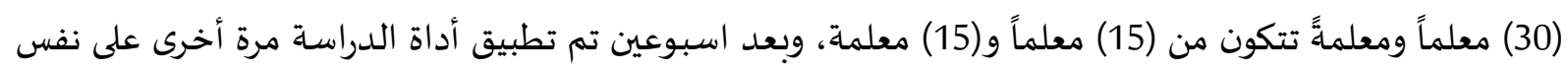

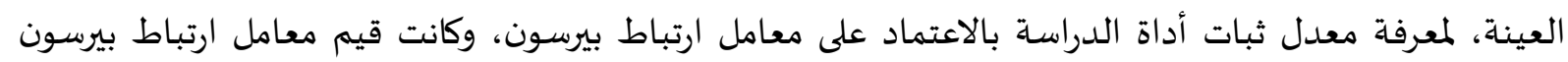

جيدة ومقبولة، كما هو موضح بالجدول (2). الجدول (2): قيم معاملات ارتباط بيرسون لمجالات الدراسة

\begin{tabular}{|c|c|c|}
\hline معامل ارتباط بيرسون & المجال & متغيرات الدراسة \\
\hline 0.83 & واقع استخدام التعليم الإلكتروني في التدريس & \multirow{2}{*}{ واقع دمج التعلم الإلكتروني في البيئة } \\
\hline 0.90 & التجهيزات الخاصة بالتعليم الإلكتروني & \\
\hline
\end{tabular}




\begin{tabular}{|c|c|c|}
\hline معامل ارتباط بيرسون & المجال ال & متغيرات الدراسة \\
\hline 0.89 & اتجاهات معلمي اللغة العربية نحو استخدام & \multirow[t]{2}{*}{ للمرحلة الابتدائية من وجهة نظر اللغية العبية بدولة الكويت } \\
\hline 0.84 & الصعوبات التي تواجه استخدام التعليم & \\
\hline 0.87 & \multicolumn{2}{|l|}{ لأداة ككل } \\
\hline
\end{tabular}

وجرى كذلك استخراج معامل الاتساق الداخلي لأداة الدراسة، بالاعتماد على اختبار كرونباخ-الفا (Cronbach- Alpha)

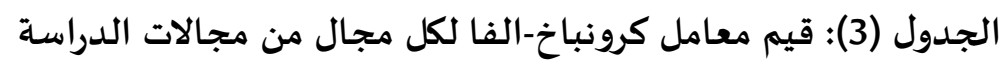

\begin{tabular}{|c|c|c|c|}
\hline معامل كرونباخ-الفا & الفقرات & المجال & 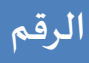 \\
\hline 0.82 & $11-1$ & واقع استخدام التعليم الإلكتروني في التدريس & 1 \\
\hline 0.84 & $21-12$ & التجهيزات الخاصة بالتعليم الإلكتروني & 2 \\
\hline 0.85 & $28-22$ & اتجاهات معلمي اللغة العربية نحو استخدام التعليم الإلكتروني & 3 \\
\hline 0.78 & $42-29$ & الصعوبات التي تواجه استخدام التعليم الإلكتروني في التدربس & 4 \\
\hline 0.87 & 42 & \multicolumn{2}{|l|}{ 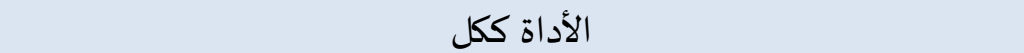 } \\
\hline
\end{tabular}

يلاحظ من الجدول (3) أنَّ معامل الثبات لجميع مجالات الدراسـة، مرتفع وهو مقياس ثبات مناسب في

$$
\text { البحوث والدراسات الإنسانية. }
$$

$$
\text { إجراءات الدراسـة }
$$

من أجل إعداد الدراسة وللخروج بالنتائج قام الباحث بالإجراءات الآتية:

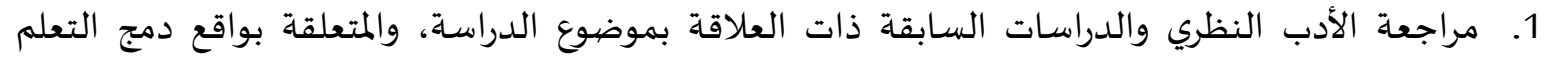

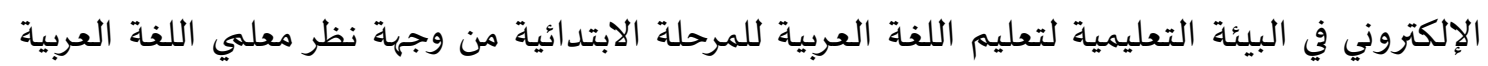
بدولة الكويت، وتم الاعتماد على الأدب النظري والدراسات السابقة في تصميم أداة الدراسـة في صورتها

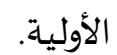
2. التأكد من الصددق الظاهري للاستبانة من خلال عرضها على مجموعة من المحكمين والأخذ بآراههم ومقترحاتهم.

3. التأكد من ثبات أداة الدراسة من خلال حسـاب معامل كرونباخ الفا للاتساق الداخلي لفقرات أداة الدراسـة. 4. توزيع الاستبانات إلكترونياً عبر نماذج قوقل.

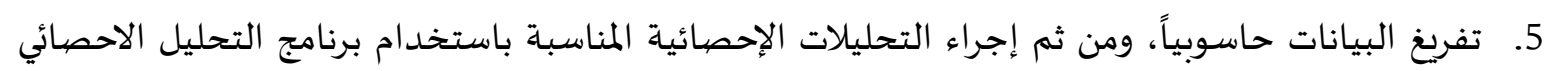
(SPSS)

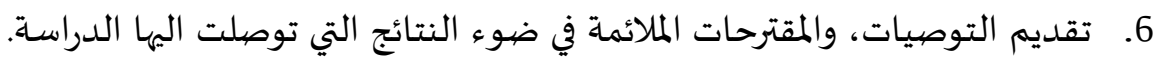

المعالجة الإحصيائية:

ههدف تحقيق أهداف الدراسة تم استخدام برنامج الرزم الإحصائية للعلوم الاجتماعية (SPSS) للإجابة عن

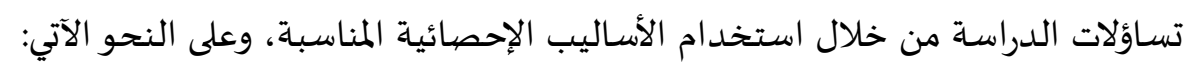


1. - التكرارات والنسب المئوية للتعرف على خصيائص عينة الدراسة.

$$
\text { 2. المتوسطات الحسابية والانحرافات المعيارية. }
$$

3. تحليل التباين الأحادي إضافة إلى اختبار شيفيه للمقارنات البعدية في حال أظهرت نتائج التباين الأحادي

4- نتائج الدراسـة ومناقشتها

النتائج المتعلقة بالسؤال الأول ومناقشتها: ما واقع دمج التعلم الإلكتروني في البيئة التعليمية لتعليم اللغة العربية للمرحلة الابتدائية من وجهة نظر معلمي اللغة العربية بدولة الكويت؟.

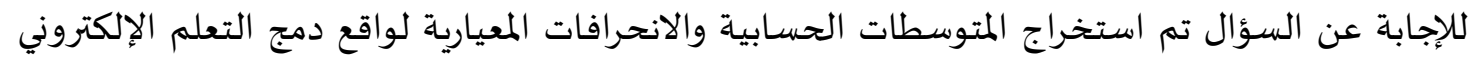
في البيئة التعليمية لتعليم اللغة العربية للمرحلة الابتدائية من وجهة نظر معلمي العربية بالكويت. والجدول (4) يبين

الجدول (4): المتوسطات الحسابية والانحرافات المعيارية والرتبة لواقع دمج التعلم الإلكتروني في البيئة

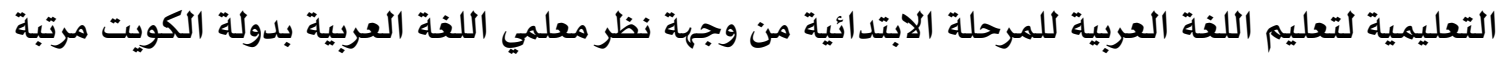
تنازليا

\begin{tabular}{|c|c|c|c|c|c|}
\hline الدرجة & الرتبة & الالتحراف & المتوسط & المجالات & رقم \\
\hline متوسطة & 1 & 0.78 & 3.50 & اتجاهات معلمي اللغة العببية نحو استخدام التعليم & 3 \\
\hline متوسطة & 2 & 0.84 & 3.49 & التجهيزات الخاصة بالتعليم الإلكتروني & 2 \\
\hline متوسطة & 3 & 0.74 & 3.47 & الصعوبات التي تواجه استخدام التعليم الإلكتروني في & 4 \\
\hline متوسطة & 4 & 0.84 & 3.44 & واقع استخدام التعليم الإلكتروني في التدريس & 1 \\
\hline متوسطة & & 0.78 & 3.45 & 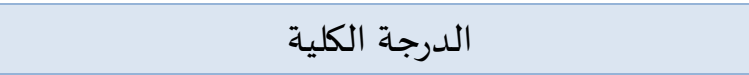 & \\
\hline
\end{tabular}

يبين الجدول (4) أنَّ المتوسط الحسابي لواقع دمج التعلم الإلكتروني في البيئة التعليمية لتعليم اللغة العربية للمرحلة الابتدائية من وجهة نظر معلمي اللغة العربية بدولة الكويت ككل (3.45)، وبانحراف (0.78)، وبدرجة متوسطة. وجاء مجال اتجاهات معلمي اللغة العربية نحو استخدام التعليم الإلكتروني في المرتبة الأولى بأعلى متوسط حسابي بلغ (3.50)، وبانحراف (0.78)، وبدرجة متوسطة، تلاه في المرتبة الثانية مجال التجهيزات الخاصة بالتعليم الإلكتروني بمتوسط حسابي بلغ (3.49)، وبانحراف (0.84)، وبدرجة متوسطة، تلاه في المرتبة الثالثة مجال

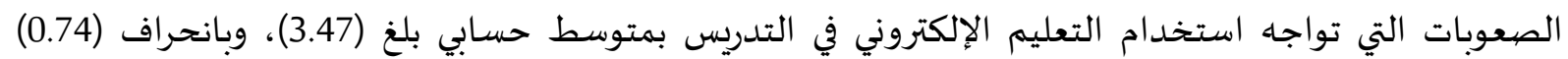

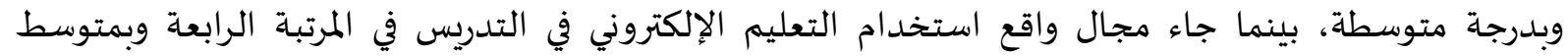

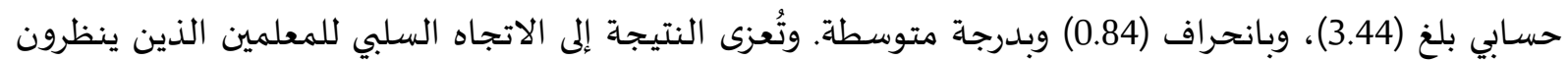

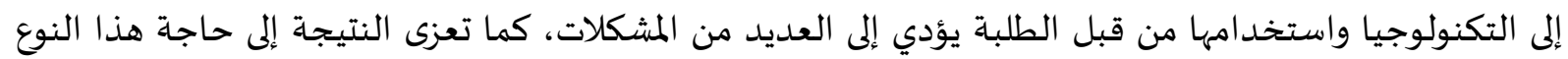

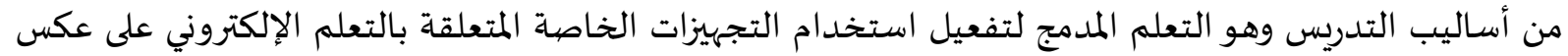
الاساليب الاعتيادية، وزيادة اهتمام وزارة التربية بهذا الجانب على عكس الاساليب التقليدية وضرورة توفير الوقت 
اللازم لأمكانية تطبيق التعلم الإلكتروني في حين أنَّ الحصة الدراسية محددة بوقت قد لا تكون كافية لتطبيق التعلم الإلكتروني.

اتفقت النتيجة مع دراسة يوين وما (Yuen \& ma, 2008) التي توصلت إلى أنَّ مدى تقبل المعلمين

لتكنولوجيا التعليم الإلكتروني والمدمج خاصة جاء بدرجة متوسطة. كما اتفقت النتيجة مع نتيجة دراسة الدليمي

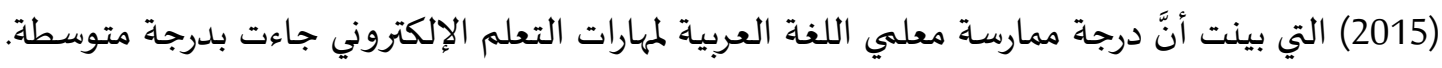

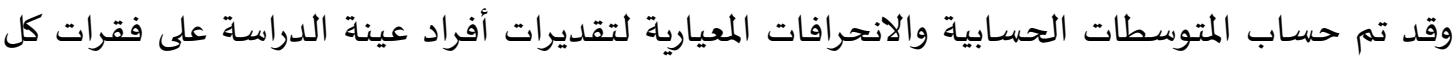
مجال منفرداً مرتبة تنازلياً، حيث كانت على المتحوات الحسابية والآنحرات

المجال الأول: اتجاهات معلمي اللغة العربية نحو استخدام التعليم الإلكتروني:

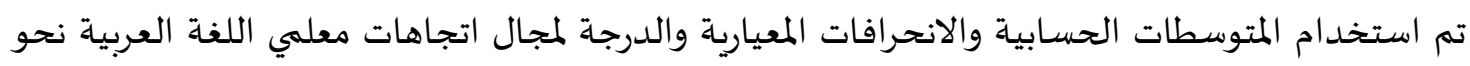
استخدام التعليم الإلكتروني، والجدول (5) يبين ذلك.

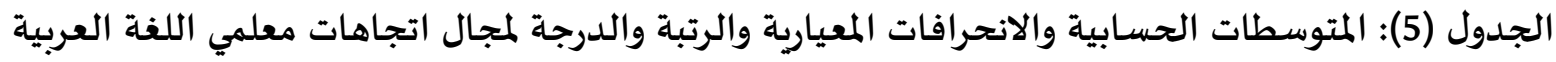
نحو استخدام التعليم الإلكتروني مرتبة تنازليا

\begin{tabular}{|c|c|c|c|c|c|}
\hline 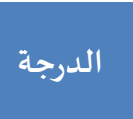 & 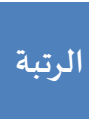 & 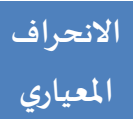 & المتوسط الحسابي & 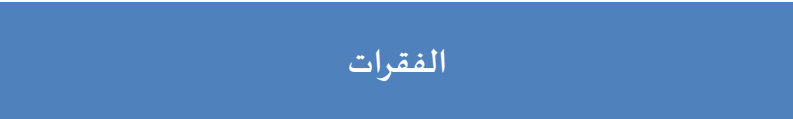 & 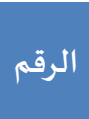 \\
\hline 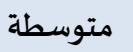 & 1 & 0.94 & 3.60 & يُعزز التعلم الإلكتروني العلاقات الاجتماعية بين المعلم والطالب. & 25 \\
\hline 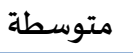 & 2 & 0.95 & 3.58 & يحسن التعلم الإلكتروني من مهارات الاتصال. & 26 \\
\hline 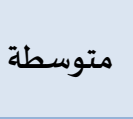 & 2 & 0.97 & 3.54 & أُفضل التعلم الإلكتروني للمساهمة في تغيير الروتين التقليدي & 24 \\
\hline 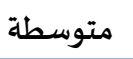 & 4 & 0.92 & 3.49 & يساعدني التعلم الإلكتروني على إنجاز مهام الطلبة التعليمية & 23 \\
\hline 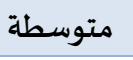 & 5 & 0.93 & 3.49 & يساعدني التعلم الإلكتروني على إجراء البحوث العلمية. & 28 \\
\hline 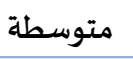 & 5 & 0.91 & 3.36 & يساعدني التعلم الإلكتروني على تطوير المهارات التقنية. & 27 \\
\hline 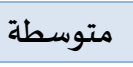 & 7 & 0.88 & 3.35 & تتوفر لديَّ الرغبة في استخدام التعلم الإلكتروني. & 22 \\
\hline متوسطة & & 0.78 & 3.50 & الدرجة الكلية & \\
\hline
\end{tabular}

يبين الجدول (5) أن المتوسط الحسابي لمجال اتجاهات معلمي اللغة العربية نحو استخدام التعليم

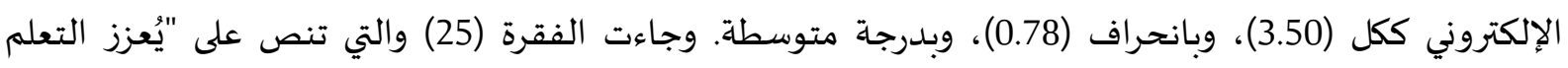

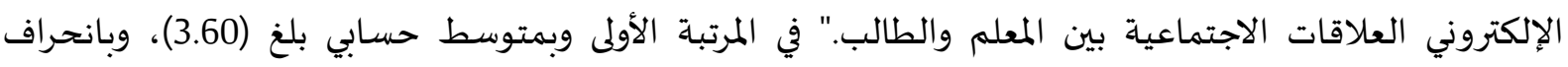
(0.94) وبدرجة متوسطة، بينما جاءت الفقرة (22) ونصها " تتوفر لديَّ الرغبة في استخدام التعلم الإلكتروني."

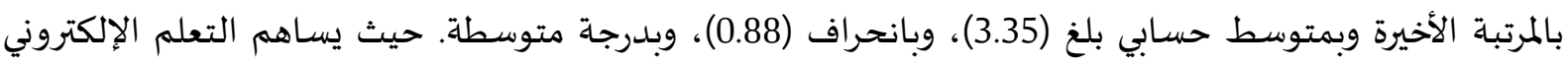

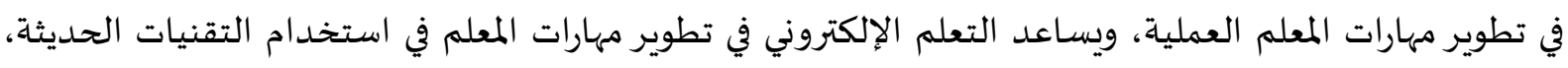

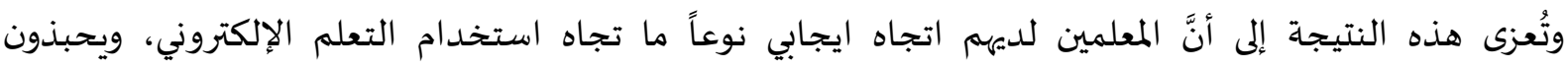

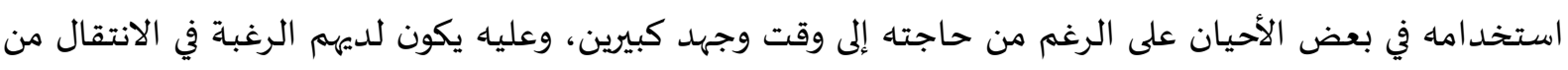

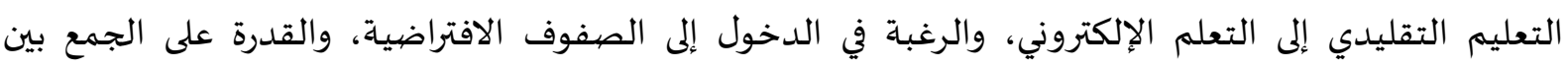

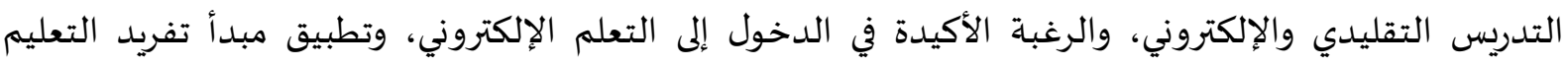

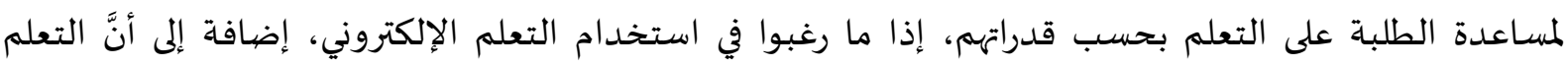

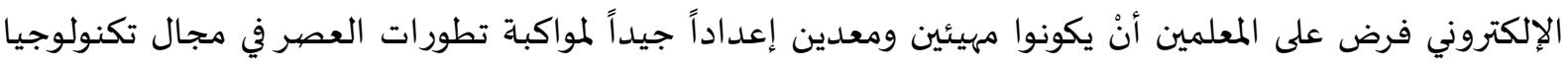
التعليم. مما يضعهم أمام صعوبات وتحديات تتطلب منهم الكثير من الجههد والوقت لتحقيق ذلكن ذلك، فلا بد أنْ يتعلموا 
أولاً كيفية استخدام تكنولوجيا المعلومات قبل أنْ يكون مطالبين باستخدامها في التعليم، وذلك من أجل أنْ يكون

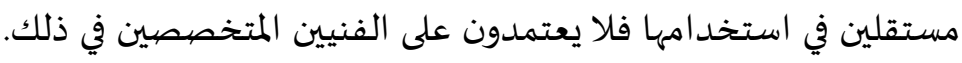

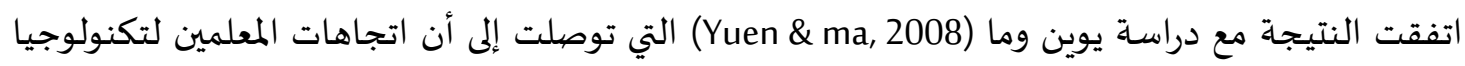

التعليم الإلكتروني والمدمج خاصة جاءت بدرجة متوسة دوسنة وماتسة

المجال الثاني: التجهيزات الخاصة بالتعليم الإلكتروني:

تم استخدام المتوسطات الحسابية والانحرافات المعيارية والدرجة لمجال التجهيزات الخاصية التحاتية بالتعليم الإلكتروني، والجدول (6) يبين ذلك.

الجدول (6): المتوسطات الحسابية والانحرافات المعيارية والرتبة والدرجة لمجال التجهيزات الخاصية بالتعليم الإلكتروني مرتبة تنازليا

\begin{tabular}{|c|c|c|c|c|c|}
\hline 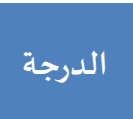 & 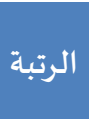 & الالمعياري & المتوسط الحسابي & 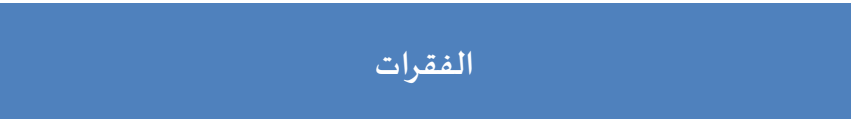 & 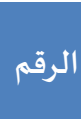 \\
\hline 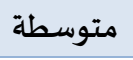 & 1 & 0.99 & 3.62 & توافر أجهزة مناسبة لمتابعة البرامج التعليمية. & 21 \\
\hline متوسطة & 2 & 0.85 & 3.51 & تعزيز القاعة التقليدية بأجهزة العرض الحديثة. & 13 \\
\hline متوسطة & 2 & 0.90 & 3.47 & تتوافر أجهزة عرض مناسبة في المدرسة. & 15 \\
\hline متوسطة & 4 & 0.86 & 3.45 & تتوافر أجهزة حاسوب كافية لأغراض التعلم المدمجج. & 19 \\
\hline متوسطة & 5 & 0.90 & 3.44 & مراعاة حاجات الطلبة عند استخدام مختبرات الحاسوب. & 12 \\
\hline متوسطة & 6 & 1.17 & 3.42 & تتوافر مصادر معلومات إلكترونية لدعم أغراض التعليم. & 16 \\
\hline متوسطة & 7 & 1.02 & 3.41 & يتوافر عدد مناسب من السبورات الذكية لعرض الدروس. & 20 \\
\hline متوسطة & 8 & 0.96 & 3.38 & إتاحة شبكة إنترنت لمعلمي اللغة العربية في المدرسة & 14 \\
\hline 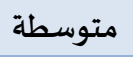 & 8 & 0.80 & 3.38 & تتوافر مصادر معلومات مطبوعة حديثة لدعم أغراض التعليم. & 17 \\
\hline متوسطة & 10 & 0.94 & 3.37 & تتوافر أجهزة متطورة يمكن استخدامها لتطوير معلمي اللغة العربية. & 18 \\
\hline 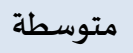 & & 0.84 & 3.49 & 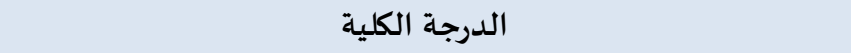 & \\
\hline
\end{tabular}

يبين الجدول (6) أنَّ المتوسط الحسابي لمجال التجهيزات الخاصة بالتعليم الإلكتروني ككل (3.49)،

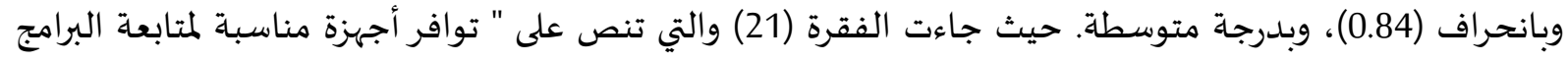

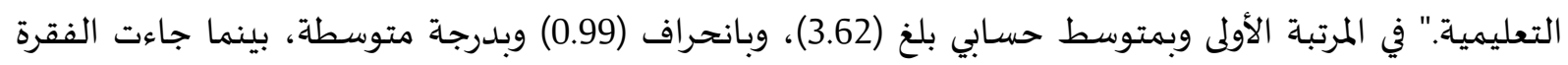
(18) ونصها " تتوافر أجهزة متطورة يمكن استخدامها لتطوير معلمي الدراسات الاجتماعية." بالمرتبة الأخيرة

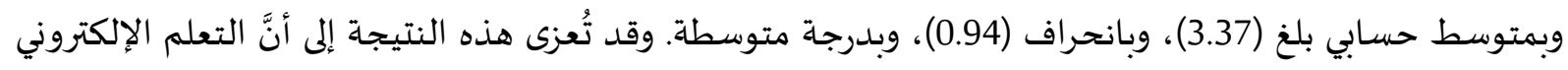

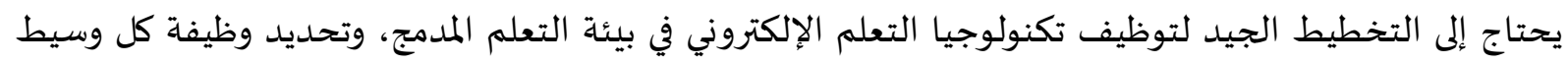

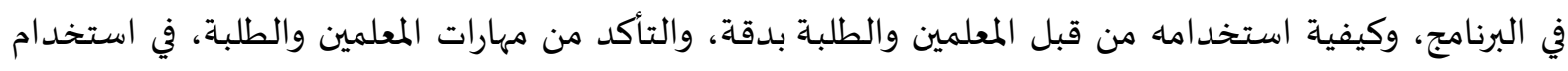

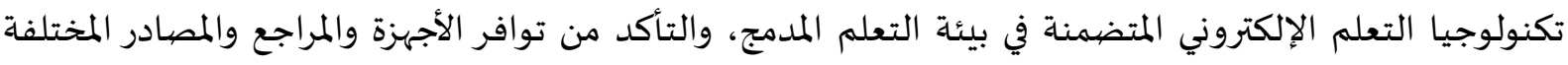

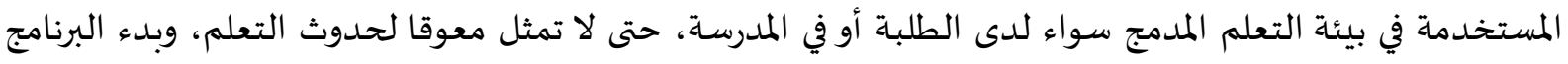

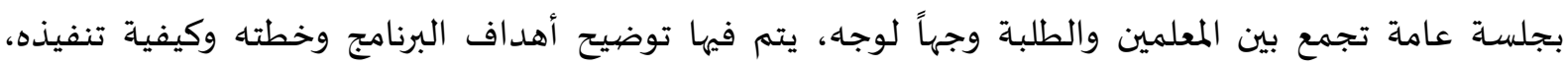

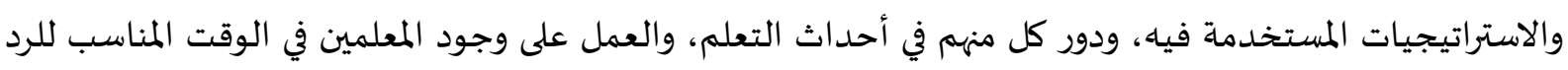

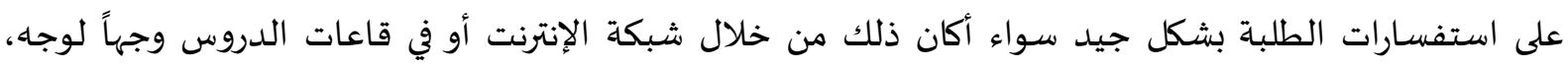
وتنوع مصادر المعلومات لمقابلة الفروق الفردية بين الطلبة. 
المجال الثالث: الصعوبات التي تواجه استخدام التعلم الإلكتروني:

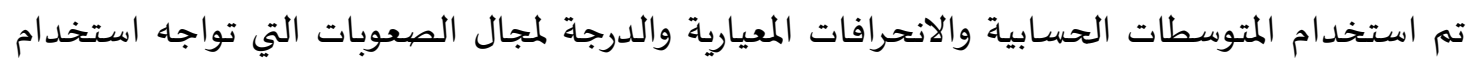

$$
\text { التعلم الإلكتروني، والجدول (7) يبين ذلك. }
$$

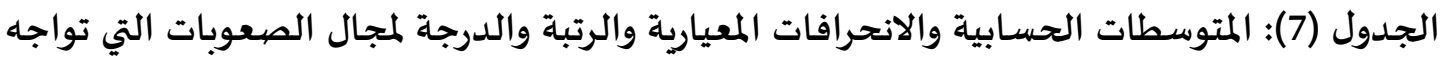

$$
\text { استخدام التعلم الإلكتروني مرتبة تنازليا }
$$

\begin{tabular}{|c|c|c|c|c|c|}
\hline 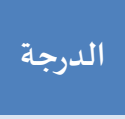 & 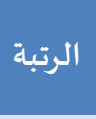 & الانديراف & المتوسـ الحسبائي & 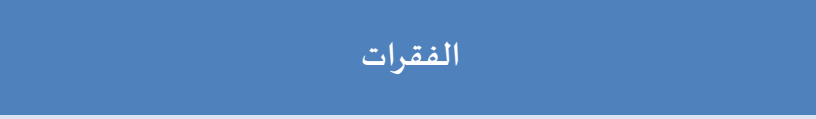 & 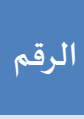 \\
\hline مرتفعة & 1 & 0.96 & 3.72 & ازدحام جدول الدروس الأسبوع للمعلمين. & 40 \\
\hline متوسطة & 2 & 0.86 & 3.63 & ازدحام الغرفة الصفية بالطلبة. & 29 \\
\hline متوسطة & 2 & 0.91 & 3.57 & ضعف الطلبة في استخدام الحاسوب. & 30 \\
\hline متوسطة & 4 & 0.89 & 3.56 & تدني مستوى معلمي اللغة العربية باللغة الإنجليزية & 32 \\
\hline متوسطة & 4 & 0.91 & 3.54 & قلة الدورات التدرببية في استخدام التقنيات المختلفة & 38 \\
\hline متوسطة & 6 & 0.94 & 3.53 & صعوبة توفير العدد الكافي من التقنيات الحديثة & 42 \\
\hline متوسطة & 7 & 0.93 & 3.50 & ضعف المواءمة بين التقنيات ومواد اللغة العربية & 36 \\
\hline متوسطة & 8 & 0.94 & 3.50 & قلة المام معلمي اللغة العربية بالتقنيات الحديثة. & 34 \\
\hline متوسطة & 9 & 0.91 & 3.49 & عدم قدرة المدرسة على توفير التقنيات الحديثة & 33 \\
\hline متوسطة & 10 & 0.83 & 3.47 & عدم توافربرامج محوسبة كافية لمواد اللغة العربية & 35 \\
\hline متوسطة & 11 & 0.99 & 3.46 & يتطلب التعلم الإلكتروني وقتا أطول. & 37 \\
\hline متوسطة & 12 & 0.92 & 3.46 & ندرة الكوادر المسؤولة عن صيانة الأجهزة الحاسوبية. & 41 \\
\hline متوسطة & 13 & 0.90 & 3.40 & صعوبة توفير أدلة متخصصية للمعلمين متخصصية بالتعلم المدمج. & 39 \\
\hline متوسطة & 14 & 1.02 & 3.14 & ضعف التدريب على أجهزة الحاسوب الحديثة. & 31 \\
\hline متوسطة & & 0.74 & 3.47 & الدرجة الكلية & \\
\hline
\end{tabular}

يبين الجدول (7) أنَّ المتوسط الحسابي لمجال الصعوبات التي تواجه استخدام التعلم الإلكتروني ككل

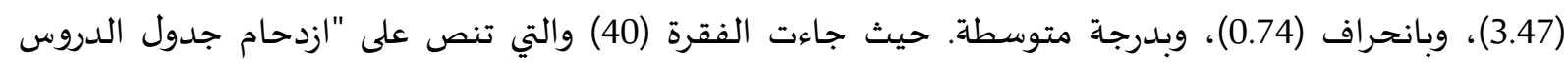

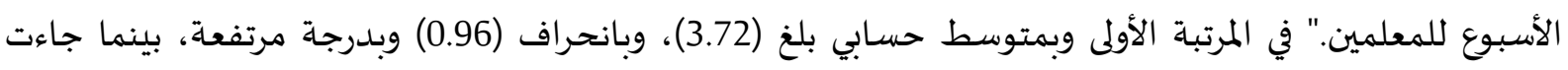

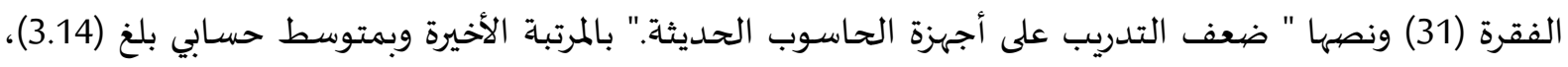

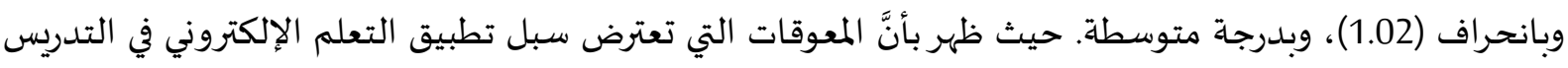

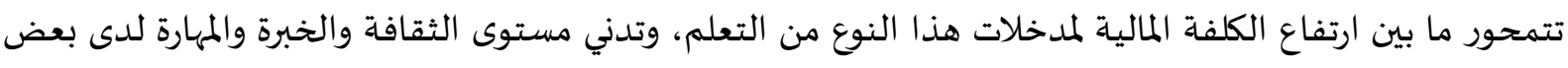

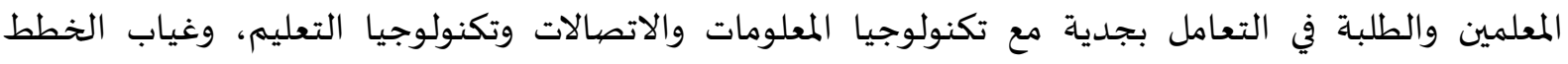

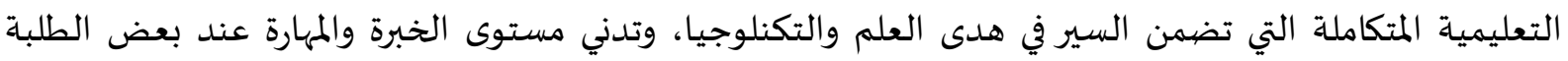

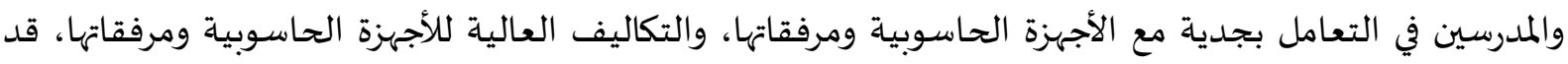

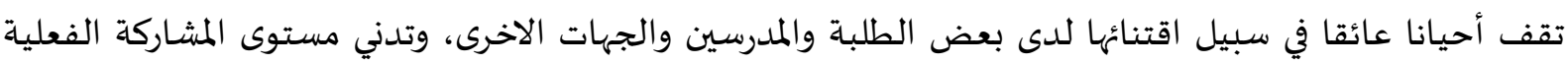

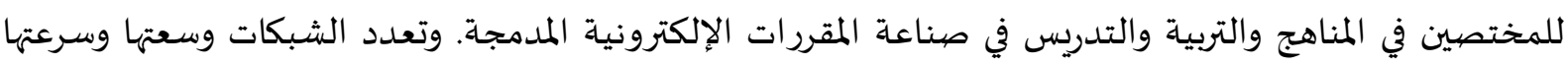

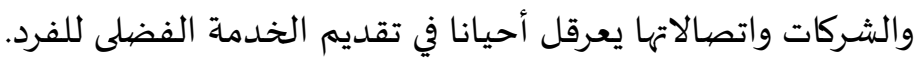

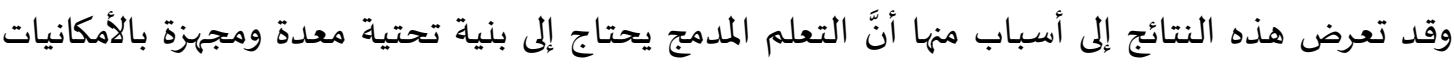

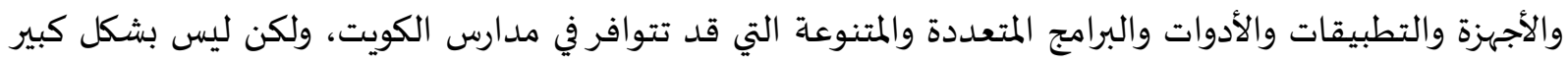

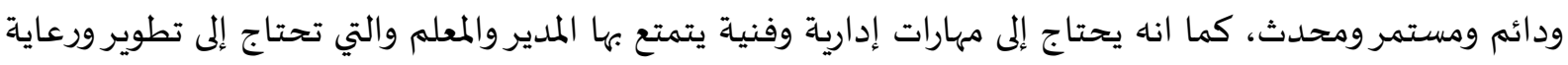


والمعلم مقارنة بالتعلم التقليدي وحده، وتمكين الطلبة من الحصول على متعة التعامل مع المعلمين وزملائهم وجهاً لوجاه، مما يعزز العلاقات الاجتماعية والجوانب الإنسانية بينهم، ومراعاة الفرق الفردية بين الطلبة بحيث يُمكن لكل متعلم السير في التعلم حسب حاجتاه وقدراته، واتساع رقعة التعلم لتشمل العالم وعدم الاقتصار على الغرفة لهربة

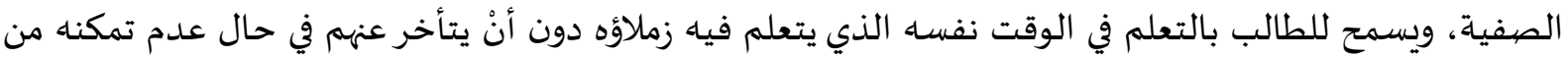
حضور الحصة الصفية لسبب ما.

النتائج المتعلقة بالسؤال الثاني ومناقشتها: هل يوجد فرق ذو دلالة احصائية عند مستوى (d =0.05) في

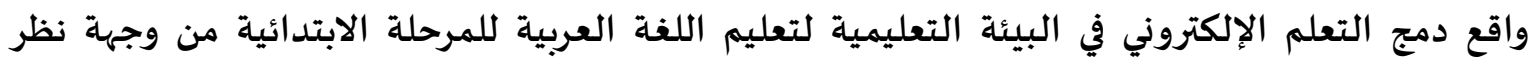

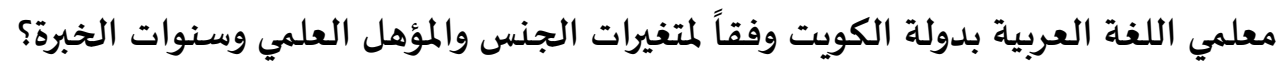
للإجابة عن السؤال تم استخراج المتوسطات الحسابية والانحرافات المعيارية لاستجابات أفراد عينة

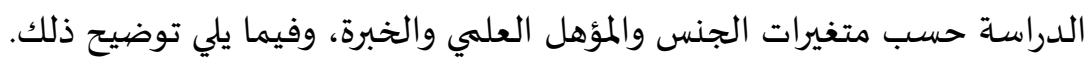

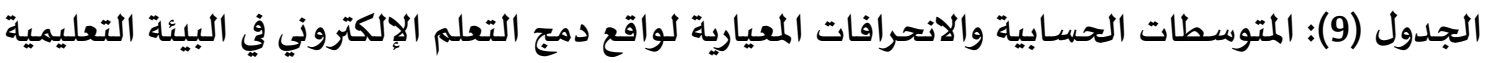

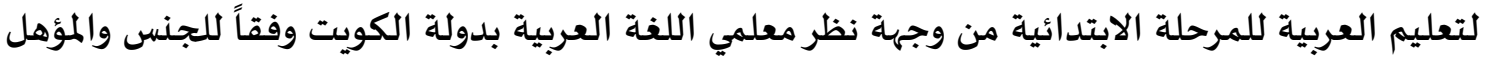
العلمي والخبرة

\begin{tabular}{|c|c|c|c|c|c|c|c|}
\hline الكلي & صعوبات & الاتجاهات نحو & تجهيزات التعليم & واقع التعلم & المتوسطات & الفئات & المتغير \\
\hline 3.53 & 3.52 & 3.66 & 3.44 & 3.49 & المتوسط الحسابي & ذكر & \multirow{2}{*}{ الجنس } \\
\hline 3.59 & 3.53 & 3.60 & 3.61 & 3.61 & المستوسط الحسبي & أنثى & \\
\hline 3.36 & 3.48 & 3.35 & 3.30 & 3.32 & المتوسط الحسبي & بكالوريوس & \multirow{2}{*}{ الملمي } \\
\hline 3.76 & 3.57 & 3.91 & 3.75 & 3.78 & المستوسط الحسبي & عليا & \\
\hline 3.61 & 3.96 & 3.95 & 2.98 & 3.54 & المستوسط الحسبي & سنل من 10 & \multirow{2}{*}{ سنوات } \\
\hline 3.69 & 3.80 & 3.91 & 3.31 & 3.76 & المستوسط الحسبي & سكثر من 10 & \\
\hline
\end{tabular}

يبين الجدول (9) تبايناً ظاهرياً في المتوسطات الحسابية والانحرافات المعيارية في استجابات عينة الدراسة

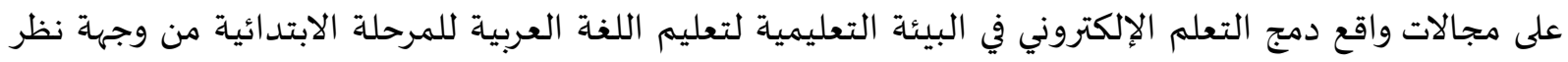
معلمي اللغة العبية بدولة الكويت وفقاً للجنس والمؤهل العلمي والخبرة، ولبيان دلالة الفرق الإحصائية بين الإنيان

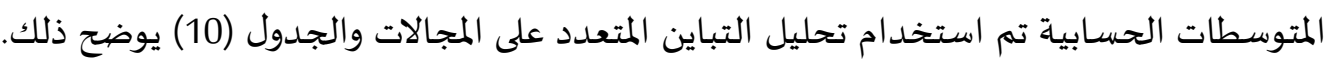
الجدول (10): تحليل التباين الثلاثي لأثر الجنس والمؤهل العلمي وسنوات الخبرة على المبلى استجابات عيندة المبات الدراسـة على مجالات أداة الدراسة

\begin{tabular}{|c|c|c|c|c|c|c|}
\hline الإحصهائية الدلالة & قيمة ف & متوسط المربعات & الحربة & المربعات مجموع & المجالات & مصدر التباين \\
\hline .313 & 1.020 & .582 & 1 & .582 & واقع استخدام التعلم الإلكتروني & الجنس الجن \\
\hline
\end{tabular}


المجلة العربية للطوم ونشر الأبحاث ـ مجلة العلوم التريوية والنفسية ـ المجلا الخامس ـ العدد الخامس والعثرون ـ يوليو 2021م

\begin{tabular}{|c|c|c|c|c|c|c|}
\hline الإحصبائية الدلة & قيمة ف & 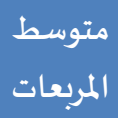 & الحربة & $\begin{array}{l}\text { مجمبوع } \\
\text { المربعات }\end{array}$ & 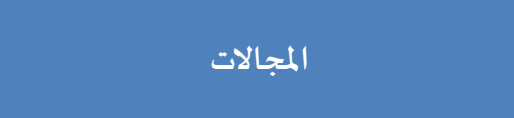 & مصبدر التباين \\
\hline .207 & 1.595 & 1.048 & 1 & 1.048 & التجهيزات الخاصة بالتعليم الإلكتروني & \multirow{4}{*}{ 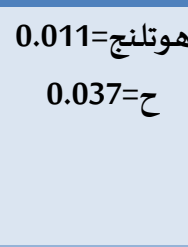 } \\
\hline .684 & .166 & .110 & 1 & .110 & اتجاهات المعلمين نحو استخدام التعليم & \\
\hline .918 & .011 & .006 & 1 & .006 & الصعوبات التي تواجه استخدام التعليم & \\
\hline .592 & .289 & .147 & 1 & .147 & المجالات ككل & \\
\hline $.000^{*}$ & 13.685 & 7.813 & 1 & 7.813 & واقع استخدام التعلم الإلكتروني & \multirow{5}{*}{ هوتلنج=حؤ=حل العلمي } \\
\hline $.001 *$ & 11.411 & 7.497 & 1 & 7.497 & التجهيزات الخاصية بالتعليم الإلكتروني & \\
\hline $.000^{*}$ & 17.277 & 11.435 & 1 & 11.435 & اتجاهات المعلمين نحو استخدام التعليم & \\
\hline $.001^{*}$ & 11.079 & 5.638 & 1 & 5.638 & الصعوبات التي تواجه استخدام التعليم & \\
\hline .443 & .591 & .340 & 1 & .340 & المجالات ككل & \\
\hline .339 & .916 & .523 & 1 & .523 & واقع استخدام التعلم الإلكتروني & \multirow{5}{*}{ ويلكس=ح=عندات الخبرة } \\
\hline .646 & .211 & .139 & 1 & .139 & التجهيزات الخاصية بالتعليم الإلكتروني & \\
\hline .093 & 2.840 & 1.880 & 1 & 1.880 & اتجاهات المعلمين نحو استخدام التعليم & \\
\hline .553 & .352 & .202 & 1 & .202 & الصعوبات التي تواجه استخدام التعليم & \\
\hline \multirow[t]{11}{*}{.307} & 1.045 & .532 & 1 & .532 & 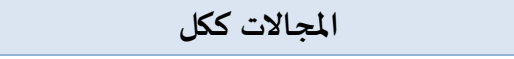 & \\
\hline & & .571 & 326 & 186.128 & واقع استخدام التعلم الإلكتروني & \multirow{5}{*}{ 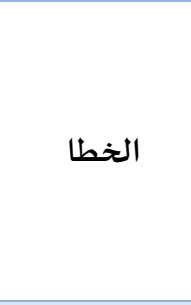 } \\
\hline & & .657 & 326 & 214.167 & التجهيزات الخاصة بالتعليم الإلكتروني & \\
\hline & & .662 & 326 & 215.772 & اتجاهات المعلمين نحو استخدام التعليم & \\
\hline & & .575 & 326 & 187.408 & الصعوبات التي تواجه استخدام التعليم & \\
\hline & & .509 & 326 & 165.900 & المجالات ككل & \\
\hline & & & 334 & 4191.331 & واقع استخدام التعلم الإلكتروني & \multirow{5}{*}{ الكلي } \\
\hline & & & 334 & 4200.680 & التجهيزات الخاصة بالتعليم الإلكتروني & \\
\hline & & & 334 & 4295.980 & اتجاهات المعلمين نحو استخدام التعليم & \\
\hline & & & 334 & 4291.235 & الصعوبات التي تواجه استخدام التعليم & \\
\hline & & & 334 & 4205.857 & المجالات ككل & \\
\hline
\end{tabular}

يتبين من الجدول (10) ما يلي:

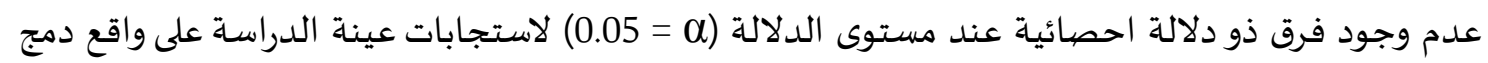

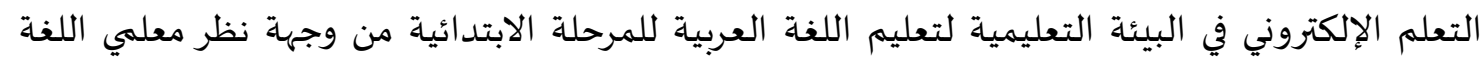
العربية بدولة الكويت بسبب اختلاف فئات الجنس في جميع المجالات. وقد تعزى هذه النتيجة إلى أنَّ

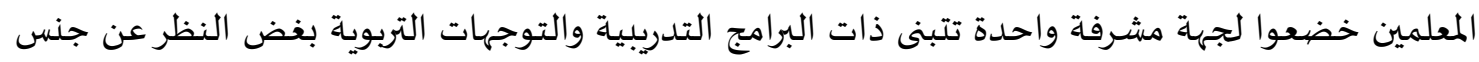

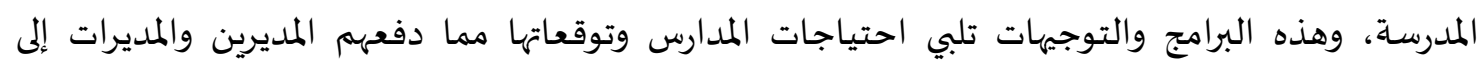
الالتزام والاهتمام والاستعداد والحرص على القيام بأنشطة تدريبية ذات علاقة بالتعلم المدمجج من أجل واتل

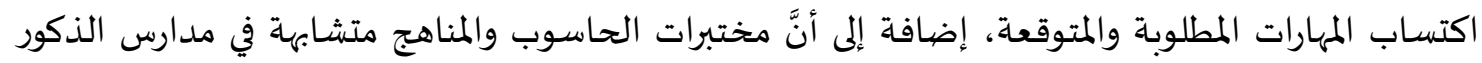

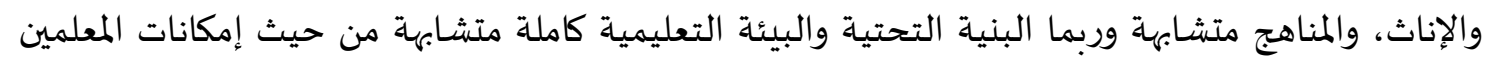

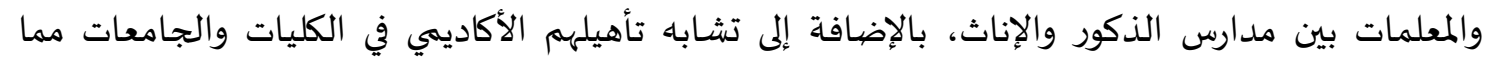
يساعد على عدم ظهور فروق بين الذكور والإناث في تقدير صعوبات تطبيق التعلم المدمجي. 
وجود فرق ذو دلالة احصائية عند مستوى الدلالة (م = 0.05) لاستجابات عينة الدراسة على واقع دمج

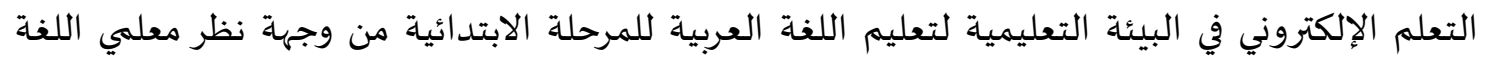
العربية بدولة الكويت ؛ بسبب اختلاف فئات المؤهل العلمي في جميع المجالات ما عدا الأداة ككل وجاءت الماتئه

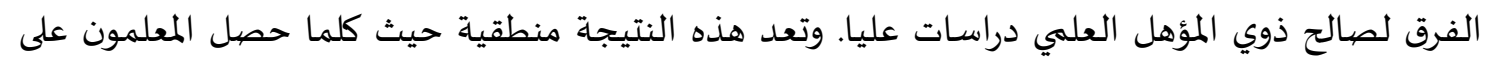

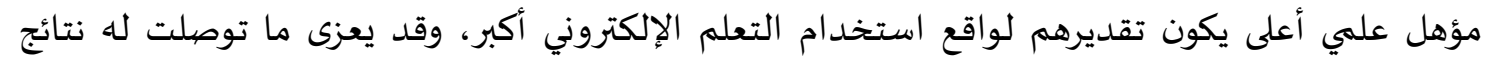
الدراسة أيضاً إلى التفهم واستيعاب المعلمين متطلبات التغيير والتطوير والعمل الفريقي، كونهم أكثر الترات

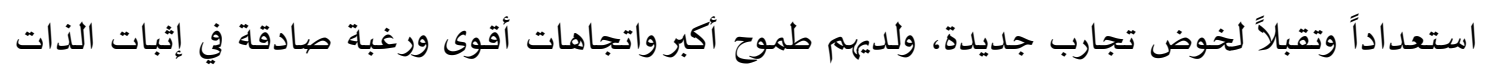

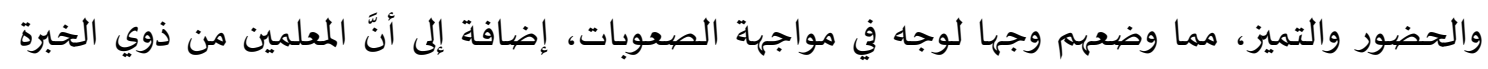

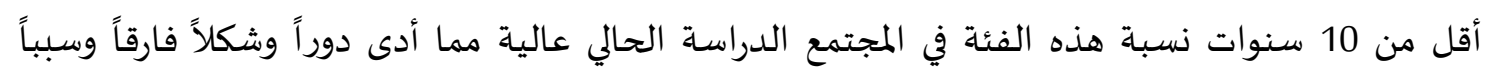
واقعياً ومنطقياً لهذه النتيجة.

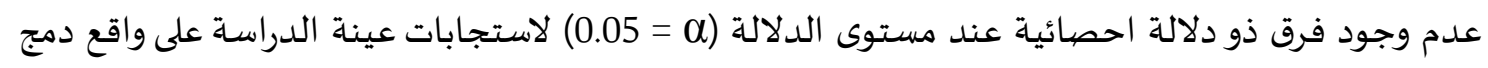

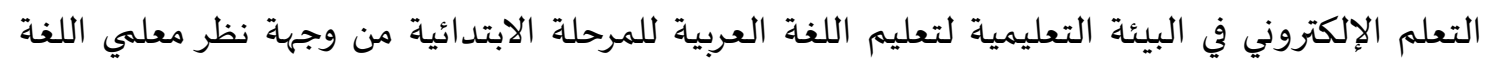

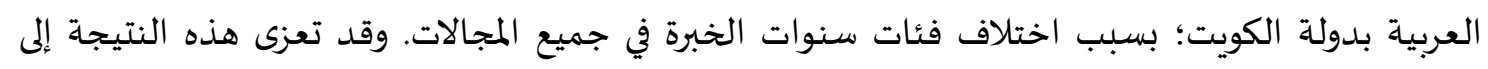

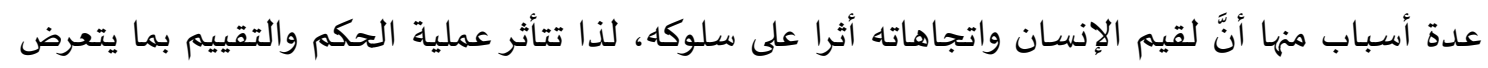

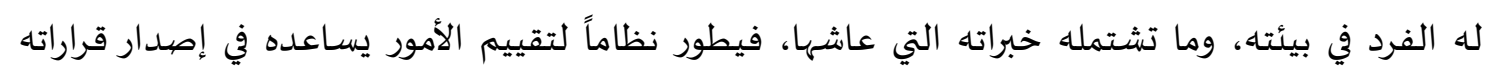

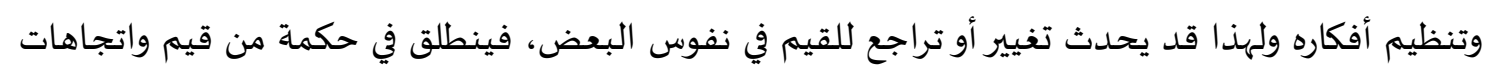

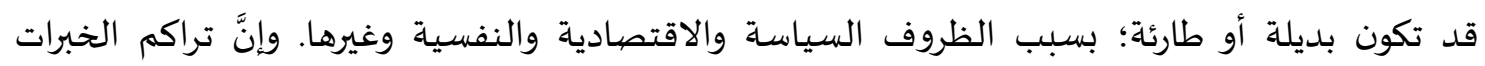

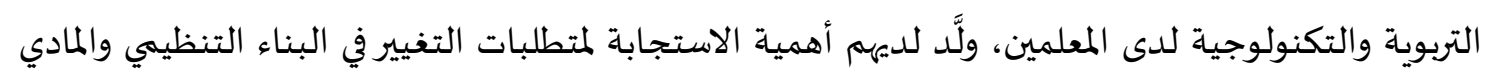
في ظل ما يعانونه من نقص في تجهيزات الغرف الصفية والمباني، وتوجها نحو العمل والإنجاز وتعظيم

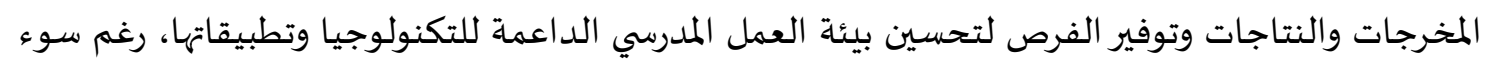

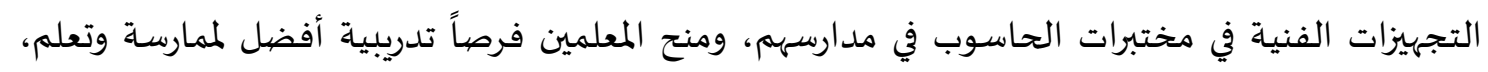

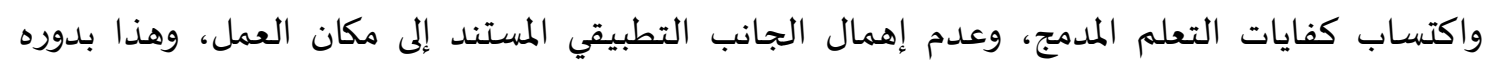

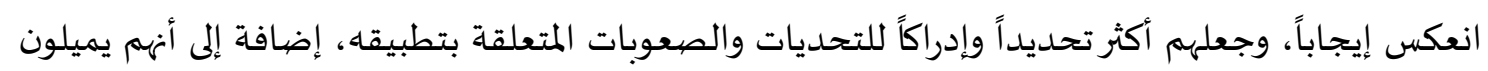

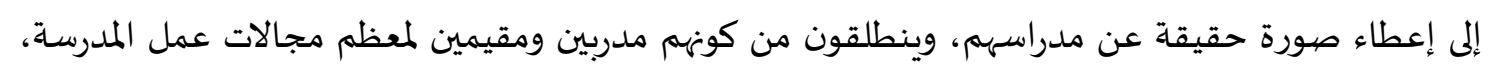

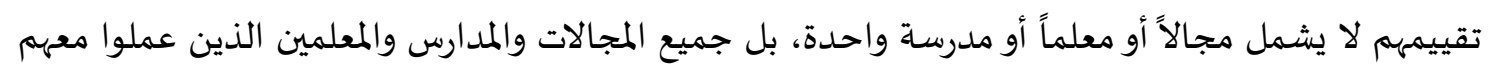
فترة خدمتهم.

\section{التوصيات والمقترحات.}

بناء على النتائج يوصي الباحث ويقترح ما يأتي:

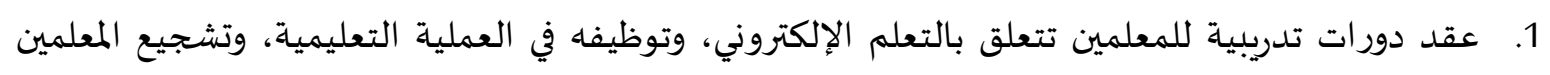

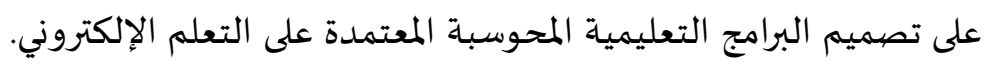

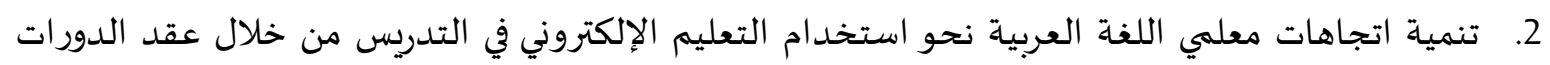
التدريبية، وتخفيض أنصبة المعلمين ليتمكنوا من تفعيل استخدام التعلم الإلكتروني في التدريس. 
3. إعادة النظر في المناهج الدراسية المدرسية، واستراتيجيات تنفيذها، من أجل استيعاب مفاهيم التقدم

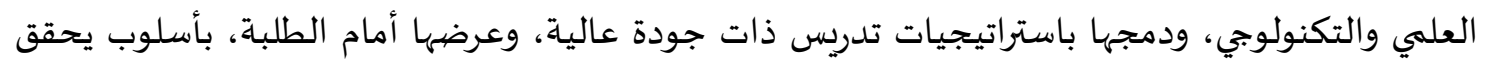

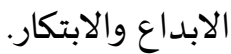

4. التأكيد على أهمية استخدام تكنولوجيا التعليم في التدريس إلى جانب تكنولوجيا المعلومات. وذلك من خلال

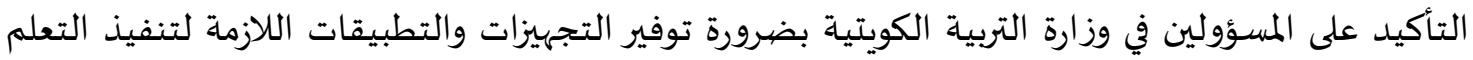
الإلكتروني. 5. إجراء دراسة حول الحلول المقترحة للصعوبات التي تواجه استخدام التعلم الإلكتروني لدى معلمي المدارس الابتدائية بدولة الكويت.

- أبو علامة، النور حسن (2017). استخدام التعليم الإلكتروني في تدريس مادة اللغة العربية لطلاب الصف مابه الثالث بمرحلة التعليم الثانوي من وجهة نظر معلمي ومعلمات المادة، رسالة ماجستير غير منشورة، جامعادة النيلين، السودان. بريكيت، أكرم بن محمد (2011). واقع التعليم الإلكتروني في تدريس اللغة العببية بالمرحلة الثانوية ومعوقات

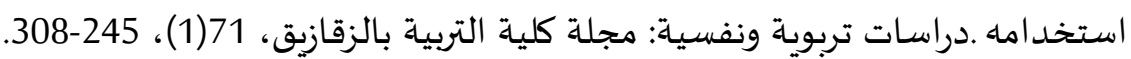
جبر، سعد والعرنوسي، ضياء (2014). التعلم المزيج وضمان الجودة في التدريس الجامعي (دراسة نظرية)، مجلة مجلة كلية التربية الاساسية، جامعة بابل، 2 (17): 152-171.

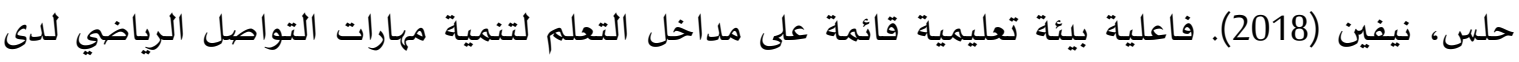
الطلبة المعاقين بصرياً بغزة، رسالة ماجستير غير منشورة، الجامعة الاسلامياة، غزة.

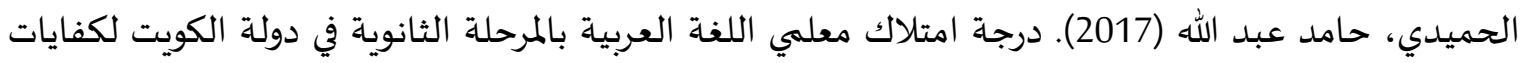

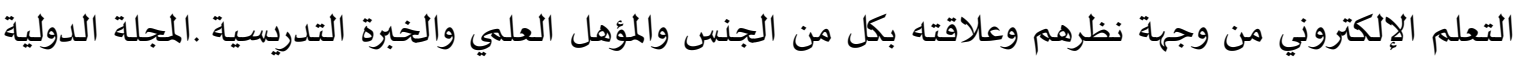

للأبحاث التربوية. 41(3): 1-48. الدليمي، صعب أحمد (2015). درجة ممارسة معلمي اللغة العربية لمهارات التعلم الإلكتروني وعلاقتها بدافعية طلبتهم نحوه، رسالة ماجستير غير منشورة، جامعة آل البيت، الاردن.

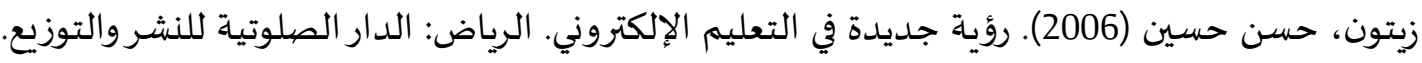

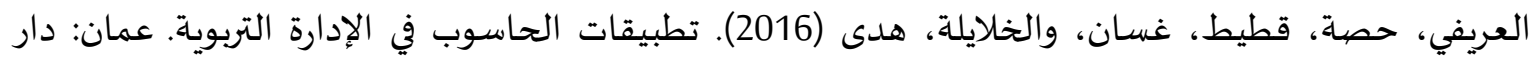
الثقافة للنشروالتوزيع. العطيوي، صالح (2018). واقع دمج التعلم الإلكتروني في البيئة التعليمية من وجهة نظر خريجي المرحلة الثانوية

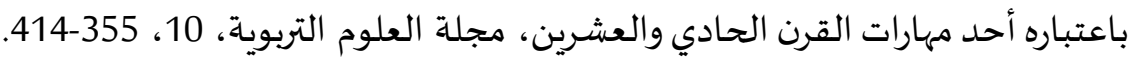

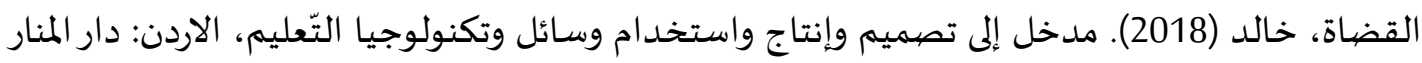
القضاة، محمد علي (2008). قضايا معاصرة في الفكر التربوي، اربد: مؤسسة حمادة للنشروالتوالتوزيع.

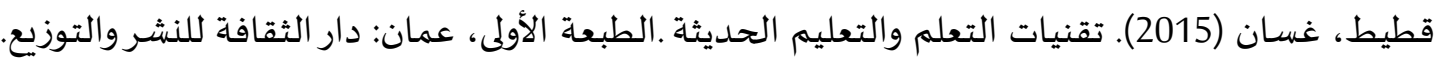


- المجالي، محمد والجراح، عبد المهدي والشناق، قسيم واليونس، يونس والعياصرة، احمد والنسور، زياد،

(2005). المسساعد العربي في تدريس انتل التعليم للجميع، دليل المدرب. وزارة التربية والتعليم، عمان-الأردان.

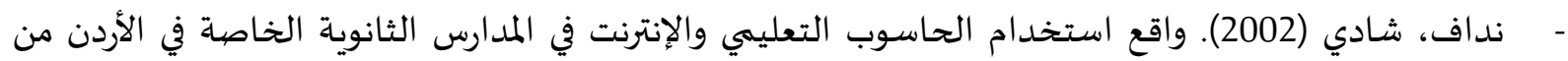
وجهة نظر المعلمين. رسالة ماجستير غير منشورة، جامعة اليرموك، الأردن.

\section{ثانياً - المراجع بالإنجليزية:}

- Alhajya, Nail \& Guenaga, Mari Luz (2016). The Extent to Which Teachers of Arabic Language in AlHisa Educational Directorate of Schools of Jordan Acquire E-Learning Competencies, International Education Studies; 9(9); 15-31.

- Carman, J. (2002). Blended Learning Design, Five Key Ingredient, Knowledge Net, Retrieved on novmber, 5, 2018.

- Yuen, A. \& Ma, W. (2008). Exploring Teacher Acceptance of E-Learning \&Blended Technology. Asia Pacific Journal of Teacher Education.36(3): 229.

- Attesseri, J. (2009). Technology briefing: Multimedia, March 2009, [http:// www.disc.cba.uh.edu/ Hirsch/spring97 /attass 1.htm.], Viewed in 19/01/2021. 